\title{
Synthesis of the repeating unit of the lipoteichoic acid of Streptococcus pneumoniae
}

\author{
Christian Marcus Pedersen ${ }^{\mathrm{a}, \mathrm{d}, *}$, Ignacio Figueroa-Perez ${ }^{\mathrm{a}}$, Artur J. Ulmer ${ }^{\mathrm{b}}$, Ulrich Zähringer ${ }^{\mathrm{b}}$, \\ Richard R. Schmidt ${ }^{\text {a,c,* }}$ \\ ${ }^{a}$ Universität Konstanz, Fachbereich Chemie, Fach 725, D-78457 Konstanz, Germany \\ ${ }^{\mathrm{b}}$ Forschungszentrum Borstel, Leibniz-Zentrum für Medizin und Biowissenschaften, Parkallee 1-40, D-23845 Borstel, Germany \\ ${ }^{c}$ Chemistry Department-Faculty of Science, King Abdulaziz University, Jeddah 21589, Saudi Arabia \\ ${ }^{\mathrm{d}}$ Department of Chemistry, University of Copenhagen, Universitetsparken 5, 2100 Copenhagen, Denmark
}

Keywords:

Gram-positive bacteria

Glycosylation

Cytokines

Lipoteichoic acic

Carbohydrates

\begin{abstract}
A B S T R A C T
The lipoteichoic acid repeating unit of Streptococcus pneumoniae is a complex pseudopentasaccharide (3). It consists of one ribitol-phosphate, one 2-acetamino-4-amino-2,4,6-trideoxy-galactose, one glucose and two galactosamine residues each differently linked, but both carrying one phosphocholine substituent, at position 6. Suitable building blocks (6-10) for efficient and diastereocontrolled ligations were designed, thus providing, after complete deprotection, the target molecule in high purity. Biological tests revealed that repeating unit 3 , lacking the lipid moiety, did not stimulate a pro-inflammatory response in human monocytes (hMNCs).
\end{abstract}

\section{Introduction}

During the onset of bacterial infections, recognition of microbial cell wall constituents occurs via pattern recognition receptors (PRRs) of the innate immune system. The recognition of these molecules of microbial origin, the so called pathogen-associated molecular patterns (PAMPs), triggers signalling pathways that activate transcription of pro-inflammatory cytokines, which participate in the generation of a rapid but nevertheless specific immune response. The most important conserved PAMPs in Gram-negative bacteria are the lipopolysaccharides (LPS, endotoxin). They are found in the outer leaflet of the outer membrane in the Gramnegative bacterial cell wall. Their potency to activate proinflammatory reactions in cells of the myeloid lineage has been known for a long time as it is extremely high. ${ }^{1,2}$

The corresponding immunostimulatory component of Grampositive bacteria was not clear for a long time. Yet, a structural counterpart to LPS called lipoteichoic acid (LTA) was found in the cell wall of Gram-positive bacteria. As LPS, LTA shares its amphiphilic nature consisting of a lipid anchor, a core oligosaccharide and

* Corresponding authors. Tel.+45 35320190 (C.M.P.); fax: +49 7531883135 (R.R.S.); e-mail addresses: cmp@chem.ku.dk (C.M. Pedersen), richard.schmidt@ uni-konstanz.de (R.R. Schmidt) the so called 'repeating unit', which is generally a negatively charged, hydrophilic glycerophosphate or ribitolphosphate residue, respectively. ${ }^{3,4}$

Streptococcus pneumoniae, one of the most common Grampositive pathogens also causes severe infections like otidis media, sinusitis and others. ${ }^{5-7}$ When reaching the lower respiratory tract or bloodstream, $S$. pneumoniae infections may result even in more life-threatening diseases like pneumonia, bacteraemia and meningitis. ${ }^{5}$ The cell wall of $S$. pneumoniae consists of several layers of peptidoglycan covalently linked to teichoic acid, and of lipoteichoic acid, that is anchored in the cell membrane. ${ }^{3,4,8}$ Structural analysis of pneumococcal LTA of the R6 strain (Scheme 1, 1) revealed that it contains phosphodiester interlinked pseudopentasaccharide repeating units each carrying two phosphocholine residues (3) and a glycolipid core structure 2 comprising a trisaccharide linked to diacylglycerol. ${ }^{9,10}$ This structural analysis was confirmed by our recent total synthesis of 1 with $\mathrm{R}=\mathrm{H}, \mathrm{X}=\mathrm{NH}_{3}^{+}$and $n=1 ;{ }^{11}$ also details of the synthesis of the core structure $\mathbf{2}$ were reported ${ }^{12}$ Biological studies with $\mathbf{1}$ and 2 showed that both compounds stimulate interleukin-8 (IL8 ) release in human monocytes (hMNCs). Since this activity was not mediated via toll-like receptor 2 (TLR2), the investigation of the biological properties of the repeating unit 3 became of interest. Hence, the overall strategy and execution of the synthesis 


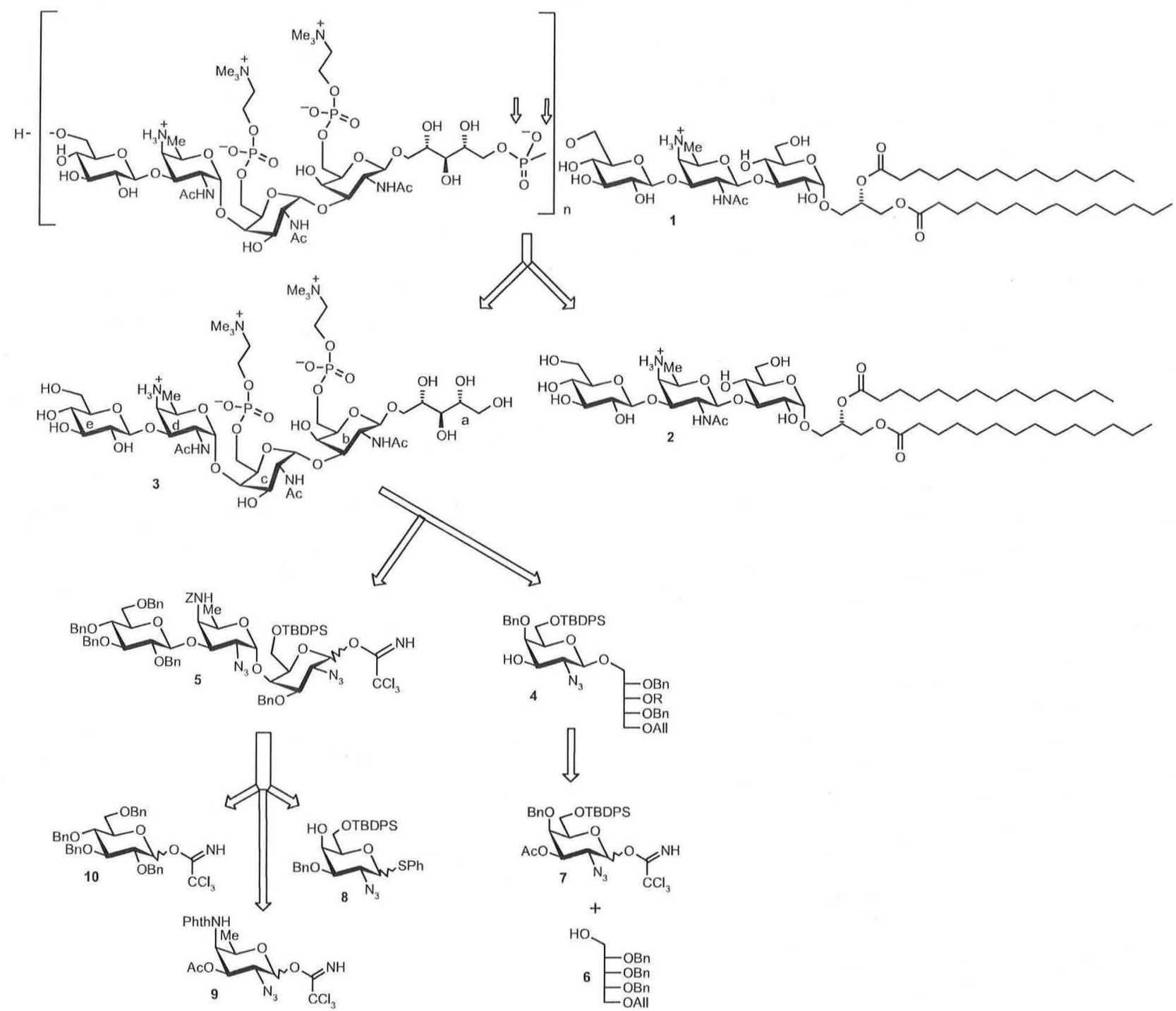

Scheme 1. Structure of the LTA of S. pneumoniae (1), the derived core structure 2 and the repeating unit $\mathbf{3}$. A retrosynthetic scheme for the synthesis of 3.

of 3 based on monosaccharide intermediates having different anomeric configurations as well as some biological results are reported in the present paper. Evidence is provided that, for biological activity of LTA in hMNCs, the lipid anchor is indispensable, whereas the pseudopentasaccharide $\mathbf{3}$ expresses no such pro-inflammatory activity.

\section{Results and discussion}

The retrosynthesis of pseudopentasaccharide $\mathbf{3}$ is displayed in Scheme 1. For a convergent synthesis strategy, disconnection between sugar residues $b$ and $c$ was chosen leading to pseudodisaccharide 4 and trisaccharicle donor $\mathbf{5}$. Hence, tert-butyldiphenylsilyl (TBDPS) groups at 6-O of sugar residues $b$ and $c$ were introduced for the regioselective attachment of the choline phosphate residues and the 5-O-allyl group at ribitol residue a was chosen for an eventual regioselective attachment of a phosphate residue as required for the total synthesis of $1{ }^{11}$ The introduction of the 2-acetylamino groups in sugar residues b, $c$ and $d$ is based on concomitant reduction of three azido groups and their subsequent $\mathrm{N}$-acetylation. Thereafter the amino group in sugar residue d can be liberated by hydrogenolysis, thus also cleaving all other $O$-benzyl protecting groups. Hence, pseudodisaccharide 4 should be available from known ribitol derivative $\mathbf{6}^{13}$ and 2-azidogalactosyl donor $\mathbf{7}$ and trisaccharide 5 from previously prepared glycosyl donors $\mathbf{9}^{12}$ and $\mathbf{1 0}^{14}$ and 4-O-unprotected 2-azido-galactosyl thioglycoside $\mathbf{8}$ as acceptor, that is, readily available from galactosamine (vide infra). After the assembly of building blocks 8-10, transformation of the resulting trisaccharicle into the corresponding trichloroacetimidate based glycosyl donor 5 will be performed. ${ }^{14}$

For the synthesis of galactose derived intermediates $\mathbf{7}$ and $\mathbf{8}$, galactosamine was transformed into tetra- $O$-acetyl-2-azido derivative $\mathbf{1 1}$ following a reported procedure (Scheme 2). ${ }^{15}$ Treatment with thiophenol in the presence of boron trifluouride ether complex afforded known phenyl thioglycoside $\mathbf{1 2}^{16}$ as a 9:7 $\alpha / \beta$ mixture. Removal of the $O$-acetyl groups with sodium methoxide in methanol and then treatment with benzaldehyde dimethyl acetal in the presence of $p$-toluenesulfonic acid ( $p$-TsOH) furnished 4,6-O-benzylidene protected derivatives $13 \alpha, \beta$ that could be readily separated. Subjecting the $\mathbf{1 3} \alpha, \beta$ mixture to different reaction sequences transformed it into the required donor 7 and into the $\mathbf{8} \alpha, \beta$ mixture, which was subsequently used to prepare 
trisaccharide donor 5. 3-O-Benzylation of $13 \alpha$ and $13 \beta$ with benzyl bromide and sodium hydride as base in DMF as solvent $(\rightarrow \mathbf{1 4} \alpha, 14 \beta)$, followed by camphorsulfonic acid (CSA) catalyzed cleavage of the 4,6-O-benzylidene group ( $\rightarrow \mathbf{1 5} \alpha, \mathbf{1 5} \beta$ ), and then regioselective 6-O-silylation with TBDPS- $\mathrm{Cl}$ in the presence of imidazole as base led to the desired building blocks $8 \alpha$ and $8 \beta$. 3O-Acetylation of $13 \alpha$ and $13 \beta(\rightarrow 16 \alpha, 16 \beta)$, then reductive opening of the 4,6-O-benzylidene group with excess borane-THF complex in the presence of 1 equiv of dibutylboron trifluoromethanesulfonate $\left(\mathrm{Bu}_{2} \mathrm{BOTf}\right)^{17}$ furnished 4-O-benzyl protected derivatives $17 \alpha$ and $17 \beta$. 6-O-Silylation with TBDPS-Cl and imidazole $(\rightarrow \mathbf{1 8} \alpha, \mathbf{1 8} \beta$ ) and then treatment with $N$-bromo-succinimide (NBS) and thereafter aqueous sodium bicarbonate led to the 1-O-unprotected 2-azido-galactopyranose derivative 19 that gave with trichloroacetonitrile in the presence of DBU as base the desired glycosyl donor 7.

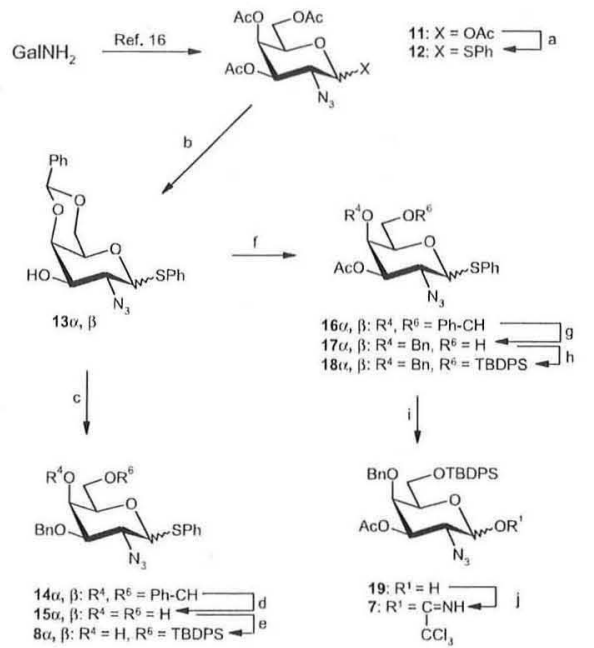

Scheme 2. Reagents and conditions: (a) $\mathrm{PhSH}, \mathrm{BF}_{3} \cdot \mathrm{OEt}_{2}, \mathrm{CH}_{2} \mathrm{Cl}_{2}$ (84\%); (b) $\mathrm{NaOMe}$ $\mathrm{MeOH} ; \mathrm{PhCH}(\mathrm{OMe})_{2}, \mathrm{p}$-TsOH, DMF, $40{ }^{\circ} \mathrm{C}(93 \%) ;($ c) $\mathrm{BnBr}, \mathrm{NaH}, \mathrm{DMF}(88 \%)$; (d) CSA $\mathrm{MeOH}, \mathrm{CH}_{2} \mathrm{Cl}_{2}$ (77\%); (e) TBDPS-Cl, imidazole, DMF (94\%); (f) $\mathrm{Ac}_{2} \mathrm{O}$, Pyr (97\%); (g) $\mathrm{H}_{3} \mathrm{~B}$ THF, $\mathrm{Bu}_{2} \mathrm{BOTf}, \mathrm{CH}_{2} \mathrm{Cl}_{2}$ (74\%); (h) TBDPS-Cl, imidazole, DMF (92\%); (i) NBS, $\mathrm{Me}_{2} \mathrm{CO}$, then aq $\mathrm{NaHCO}_{3}$ (86\%); (j) $\mathrm{CCl}_{3} \mathrm{CN}, \mathrm{DBU}, \mathrm{CH}_{2} \mathrm{Cl}_{2}(91 \%)$.

For the construction of the trisaccharide donor $\mathbf{5}$, acceptors $8 \alpha$ and $\mathbf{8} \beta$ were glycosylated with donor $\mathbf{9}$ that was obtained from glucosamine, ${ }^{12}$ with trimethylsilyl trifluoromethanosulfonate (TMSOTf) as catalyst in dichloromethane as solvent at room temperature, thus affording due to the anomeric effect, $\alpha(1-4)$ linked disaccharides $20 \alpha$ and $20 \beta$, respectively (Scheme 3 ). Cleavage of the 3d-O-benzoyl group with sodium methoxide in methanol, then removal of the $N$-phthaloyl (Phth) group with ethylenediamine ${ }^{18}$ and protection of the amino group with the benzyloxycarbonyl $(Z)$ group by treatment with $Z-C l$ in aqueous THF in the presence of sodium bicarbonate furnished $\mathbf{2 1} \alpha$ and $\mathbf{2 1} \beta$. Following glycosylation with glucosyl donor $\mathbf{1 0}^{14}$ and TMSOTf as catalyst in acetonitrile as solvent at $-40^{\circ} \mathrm{C}$, thus employing for the anomeric stereocontrol the nitrile effect, ${ }^{19}$ led to trisaccharides $22 \alpha$ and $22 \beta$. Their treatment with NBS and then with aqueous sodium bicarbonate solution gave 1-O-unprotected intermediate 23 that was transformed with trichloroacetonitrile and DBU as base into the desired trichloroacetimidate trisaccharide donor $\mathbf{5}$. It was found that under the conditions employed for the synthesis of $7,8 \alpha, 8 \beta$ and 5 from precursors $13 \alpha$ and $13 \beta$, respectively, the anomeric configuration of the intermediates had practically no influence on the transformation yields.

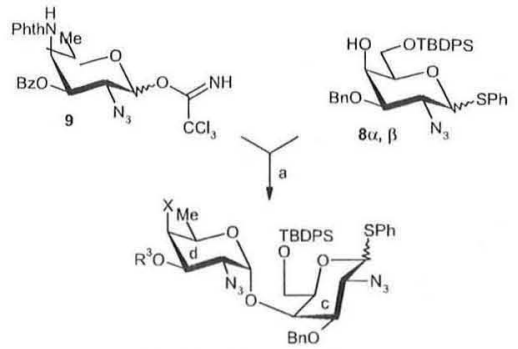

$200, \beta: R^{3 y}=B z, X=N P h$ th $\square$

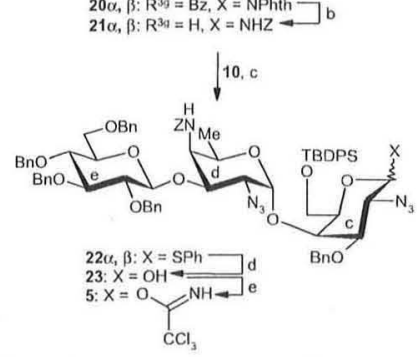

Scheme 3. Reagents and conditions: (a) TMSOTf (0.1 equiv), $\mathrm{CH}_{2} \mathrm{Cl}_{2}$ (86\%), (b) $\mathrm{NaOMe}$ $\mathrm{MeOH}$ then $\mathrm{H}_{2} \mathrm{~N}-\mathrm{CH}_{2}-\mathrm{CH}_{2}-\mathrm{NH}_{2}, \mathrm{NaOMe}, \mathrm{BuOH}$, then $\mathrm{Z}-\mathrm{Cl}, \mathrm{NaHCO}_{3}(92 \%)$; (c) TMSOTf ( 0.15 equiv), MeCN, $-40{ }^{\circ} \mathrm{C}$ (94\%), (d) NBS, $\mathrm{Me}_{2} \mathrm{CO}, \mathrm{H}_{2} \mathrm{O},-15{ }^{\circ} \mathrm{C}(91 \%)$; (e) $\mathrm{CCl}_{3} \mathrm{CN}$, DBU, $\mathrm{CH}_{2} \mathrm{Cl}_{2}$ (71\%, two steps).

The pseudodisaccharide $\mathbf{4}$ was readily obtained from glycosyl donor 7 and 1-O-unprotected ribitol derivative $\mathbf{6}$ (Scheme 4 ). ${ }^{13}$ Activation of 7 with catalytic TMSOTf as catalyst and employing the nitrile effect ${ }^{19}$ afforded the desired $\beta(1-1)$-linkage furnishing glycoside 24 that on treatment with sodium methanolate in methanol led to the desired acceptor 4 .

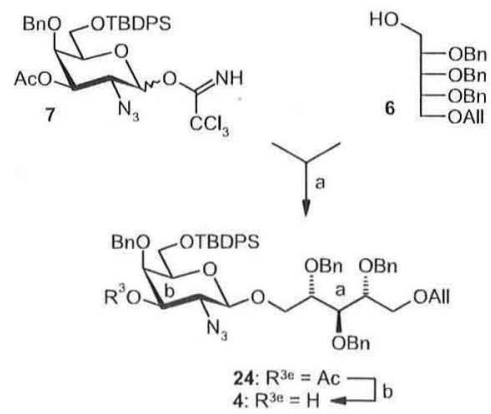

Scheme 4. Reagents and conditions: (a) TMSOTf (0.1 equiv), MeCN, $-40{ }^{\circ} \mathrm{C}(88 \%)$; (b) $\mathrm{NaOMe}, \mathrm{MeOH}$ (quantitative).

Glycosylation of acceptor $\mathbf{4}$ with trisaccharide donor $\mathbf{5}$ under standard conditions for $\alpha$-anomeric stereocontrol afforded the desired $\alpha(1-3)$-linkage between sugar residues $\mathrm{b}$ and $\mathrm{c}$ furnishing pseudopentasaccharide 25 in high yield (Scheme 5). Transformation of the three azido groups into amino groups required some experimentation; ${ }^{20}$ finally the use of hydrogen sulfide in aqueous pyridine afforded very good results and, after $\mathrm{N}$-acetylation with acetic anhydride in pyridine, compound $\mathbf{2 6}$ was obtained in good overall yield. Selective 6b,6c-O-desilylation was readily performed with HF-pyridine complex furnishing compound 28. Ligation with choline phosphate residues using phosphite building block $\mathbf{2 9}^{21}$ was performed with tetrazole as catalyst followed by oxidation of the phosphite intermediate with tert-butylhydroperoxide to the phosphate stage. Treatment with dimethylamine led to 


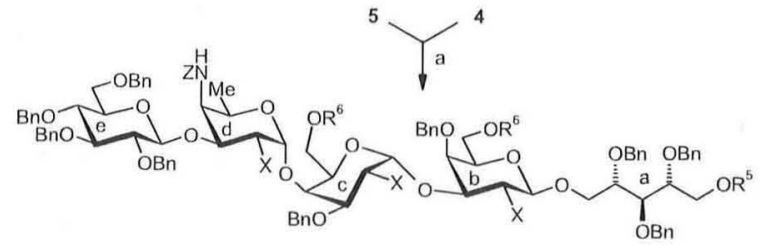

25: $X=N_{3}, R^{5 a}=$ All, $R^{6 b}=R^{6 c}=$ TBDPS
26: $X=N H A c, R^{5 a}=A l l, R^{6 b}=R^{6 c}=T B D P S$
28: $X=N H A c, R^{5 a}=A l l, R^{6 b}=R^{6 c}=H \longrightarrow 27: X=N H A c, R^{5 a}=H$,
$R^{6 b}=R^{6 c}=T B D P S$

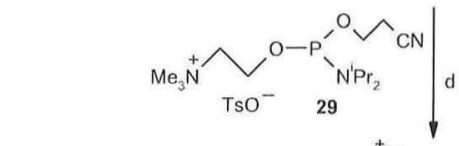

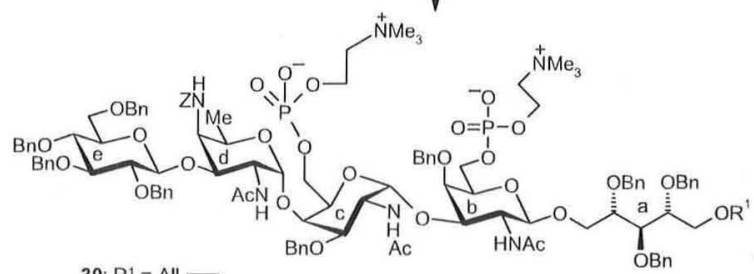

30: $R^{1}=$ All $\square$

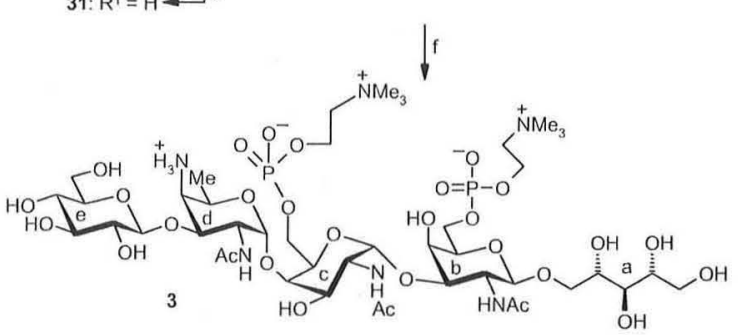

Scheme 5. Reagents and conditions: (a) TMSOTf, $\mathrm{CH}_{2} \mathrm{Cl}_{2}$ (89\%); (b) $\mathrm{H}_{2} \mathrm{~S}$, $\mathrm{Pyr}, \mathrm{H}_{2} \mathrm{O}$, then $\mathrm{Ac}_{2} \mathrm{O}$, Pyr (84\%); (c) HF, Pyr (91\%); (d) tetrazole, $\mathrm{MeCN}$, then $t-\mathrm{BuO}_{2} \mathrm{H}(72 \%)$; (e) $\left(\mathrm{Ph}_{3} \mathrm{P}\right)_{3} \mathrm{RuCl}_{2}$ (0.05 equiv), DBU, EtOH, then $\mathrm{HCl}, \mathrm{Me}_{2} \mathrm{CO}(26-27$ 77\%; 30-31 87\%); (f) $\mathrm{H}_{2}, \mathrm{Pd}(\mathrm{OH})_{2}, \mathrm{MeOH}(44 \%)$.

removal of the cyanoethyl groups furnishing pseudopentasaccharide 30 carrying the desired phosphocholine residues at $6 \mathrm{~b}$ $O$ and $6 \mathrm{c}-O$. The $5 \mathrm{a}-\mathrm{O}-\mathrm{allyl}$ group was cleaved by isomerization with catalytic tris(triphenylphosphine)ruthenium dichloride ${ }^{22}$ and DBU as base in ethanol, followed by acid treatment ( $p$-TsOH in methanol or $\mathrm{HCl}$ in acetone) furnishing compound 31. Similar treatment of fully protected pseudopentasaccharide $\mathbf{2 6}$ afforded 6-O-deallylated compound 27, that is useful for other modifications. Compound 27 was investigated for the introduction of the choline phosphate residue at a late stage of the attempted total synthesis of $S$. pneumonice LTA 1. ${ }^{20}$ However, the required TBDPS cleavage in the presence of a phosphate was not selective. Hence, an alternative route was chosen for the reported total synthesis of $\mathbf{1}^{11}$ The final deprotection of $\mathbf{3 1}$ relied on hydrogenolytic O-debenzylation with Pearlman's catalyst. The purification of the crude material was performed on reversed-phase silica gel (SEP-Pak $\mathrm{C}_{18}$ ) and gel phase chromatography (GPC) in order to remove salt contaminants, thus affording target molecule $\mathbf{3}$ whose structure was fully confirmed by ${ }^{1} \mathrm{H},{ }^{13} \mathrm{C}$ NMR spectroscopy and mass data (Table 1 ).

\subsection{Biological studies}

The induction of interleukin-8 (IL-8) by $\mathbf{3}$ was tested in human peripheral blood cells using stimulation of isolated human mononuclear cells (hMNCs) as well as whole blood assay (data not given). Both tests revealed that, by contrast to what was found for $\mathbf{1}$ and $2{ }^{11,12}$ the pentasaccharide representing the de-phosphorylated repeating unit in S. pneumoniae LTA 3 did not stimulate IL-8
Table 1

\begin{tabular}{|c|c|c|c|c|c|}
\hline Sugar & e $(\beta-G l c)$ & $d(\alpha-A A T)$ & $\begin{array}{l}\mathrm{c} \\
(\alpha-\text {-GalNAc })\end{array}$ & $\begin{array}{l}\text { b } \\
(\beta-G a \mid N A c)\end{array}$ & $\begin{array}{l}\text { a } \\
\text { (Ribitol) }\end{array}$ \\
\hline $1-\mathrm{H}$ & $4.61\left(J_{1,2} 7.9\right)$ & $4.98\left(J_{1,2} 4.1\right)$ & $5.20\left(J_{1.2} 3.9\right)$ & $4.67\left(J_{1,2} 8.5\right)$ & 3.98 \\
\hline $1-\mathrm{H}^{\prime}$ & - & - & - & - & 4.03 \\
\hline $2-\mathrm{H}$ & $3.34\left(J_{2,3} 9.0\right)$ & 4.30 & 4.37 & 4.15 & 4.02 \\
\hline $3-\mathrm{H}$ & $3.50\left(J_{3.4} 9.0\right)$ & $4.42\left(J_{3.4} 9.2\right)$ & 3.95 & 3.89 & 3.80 \\
\hline $4-\mathrm{H}$ & $3.46\left(J_{4,5} 9.3\right)$ & 3.91 & 4.14 & 4.19 & 3.72 \\
\hline $5-\mathrm{H}$ & 3.48 & $4.81\left(J_{4.5} 1.8\right)$ & 4.00 & 3.80 & 3.68 \\
\hline $5-\mathrm{H}^{\prime}$ & - & - & - & - & 3.83 \\
\hline $6-\mathrm{H}$ & 3.78 & $1.27\left(J_{5,6} 6.5\right)$ & 4.03 & 4.10 & \\
\hline $6-\mathrm{H}^{\prime}$ & 3.92 & & 4.06 & 4.10 & \\
\hline$C-1$ & 104.7 & 98.9 & 94.0 & 101.8 & 70.0 \\
\hline$C-2$ & 73.3 & 48.8 & 49.9 & 51.1 & 71.1 \\
\hline$C-3$ & 76.3 & 75.2 & 67.3 & 74.8 & 72.5 \\
\hline$C-4$ & 69.7 & 55.5 & 77.2 & 63.7 & 72.4 \\
\hline$C-5$ & 76.0 & 63.8 & $71.0\left(U_{c, p} 6.1\right)$ & $74.0\left(U_{C, P} 8.5\right)$ & 62.9 \\
\hline C-6 & 60.9 & 15.9 & $64.0\left(U_{C, P} 4.3\right)$ & $65.0\left(U_{C, P} 5.5\right)$ & - \\
\hline \multicolumn{6}{|c|}{ Choline residues } \\
\hline $1 \mathrm{~b}-\mathrm{H} / \mathrm{H}^{\prime}$ & $\begin{array}{l}4.35\left(J_{1,1}, 11.5,\right. \\
\left.J_{1,2} 4.0\right)^{\mathrm{c}}\end{array}$ & & $C-1 b$ & $60.0\left(J_{C, P} 4.9\right)$ & \\
\hline $1 \mathrm{c}-\mathrm{H} / \mathrm{H}^{\prime}$ & $\begin{array}{l}4.29\left(J_{1,1^{\prime}} 11.2,\right. \\
\left.J_{1,2} 3.8\right)^{\mathrm{c}}\end{array}$ & & $\mathrm{C}-1 \mathrm{c}$ & 60.0 & \\
\hline $2 \mathrm{~b}-\mathrm{H} / \mathrm{H}^{\prime}$ & 3.69 & & $C-2 b$ & $66.3\left(U_{C . P} 4.9\right)$ & \\
\hline $2 \mathrm{c}-\mathrm{H} / \mathrm{H}^{\prime}$ & 3.69 & & $C-2 c$ & $66.3\left(J_{C, P} 4.9\right)$ & \\
\hline$+\mathrm{N}\left(\mathrm{CH}_{3}\right)_{3}$ & 3.25 & & $+\mathrm{N}\left(\mathrm{CH}_{3}\right)_{3}$ & 54.5 & \\
\hline$+\mathrm{N}\left(\mathrm{CH}_{3}\right)_{3}$ & 3.25 & & $+\mathrm{N}\left(\mathrm{CH}_{3}\right)_{3}$ & 54.5 & \\
\hline $\begin{array}{l}\text { N-Acetyl gr } \\
\text { NAC }(C=0)\end{array}$ & oups & & $\begin{array}{l}{ }^{13} \mathrm{C}: 175.3 \\
175.2,175.0\end{array}$ & & \\
\hline $\mathrm{NAC}\left(\mathrm{CH}_{3}\right)$ & $\begin{array}{l}{ }^{1} \mathrm{H}: 2.15, \\
2.12,2.08\end{array}$ & & $\begin{array}{l}{ }^{13} \mathrm{C}: 22.9 \\
22.6,22.5\end{array}$ & & \\
\hline
\end{tabular}

a $\delta(\mathrm{ppm}) ; J(\mathrm{~Hz})$

${ }^{b}$ Homo- $\left({ }^{1} \mathrm{H}\right)$ and ${ }^{1} \mathrm{H},{ }^{13} \mathrm{C}$-heteronuclear NMR spectra (HMQC) were recorded with a Bruker Advance DPX-360 spectrometer at $360.1 \mathrm{MHz}\left({ }^{1} \mathrm{H}\right)$ and $90.6 \mathrm{MHz}\left({ }^{13} \mathrm{C}\right)$, respectively, at $300 \mathrm{~K}$ in $\mathrm{D}_{2} \mathrm{O}$; chemical shifts were referenced to internal sodium 3 trimethylsilyl-propionate- $d_{4}\left(\mathrm{TSP}, \delta_{\mathrm{H}}, \delta_{\mathrm{C}} 0.0\right.$ ).

c Assignments may have to be reversed.

release indicating that the lipophilic part of $\mathbf{1}$ and $\mathbf{2}$ is necessary for contributing to the biological activity identified (Fig. 1). It was also found that, like $\mathbf{1}$ and $\mathbf{2 , 3}$ did not sense toll-like receptor 2 (TLR2) as well as TLR4/MD2/CD14 (data not shown), further indicating that the preparations were free of contaminating bacterial LPS and lipopeptide, respectively.

In previous work we also showed that the glycolipid core structure 2 consisting of a trisaccharide bound to the lipid anchor exhibits qualitatively and quantitatively the same biological profile as 1 and activates the release of IL-8 in hMNCs. ${ }^{12}$ From those data we already concluded that the lipid anchor and part of the attached oligosaccharide mediate the biological activities of LTA. For $\mathbf{1}$ as well as for $\mathbf{2}$ and $\mathbf{3}$, it was found that this activity neither correlated to TLR2 nor to TLR4 indicating that other receptors of the innate immune system, such as the lectin pathway of the complement system might be the most likely PRR for $\mathbf{1}$ and $\mathbf{2}$. Based on the results obtained with the pseudopentasaccharide of the repeating unit (3), this hypothesis has now gained further credence.

\section{Conclusions}

The pseudopentasaccharide repeating unit of S. pneumoniae RG strain could be efficiently prepared from ribose, galactosamine, glucosamine and glucose precursors based on O-glycosyl trichloroacetimidates as glycosyl donors. For the anomeric stereocontrol the anomeric effect and the nitrile effect, respectively, were employed. Final deprotection led to target molecule $\mathbf{3}$ in high purity. This molecule, lacking a lipid moiety did not induce an immune 


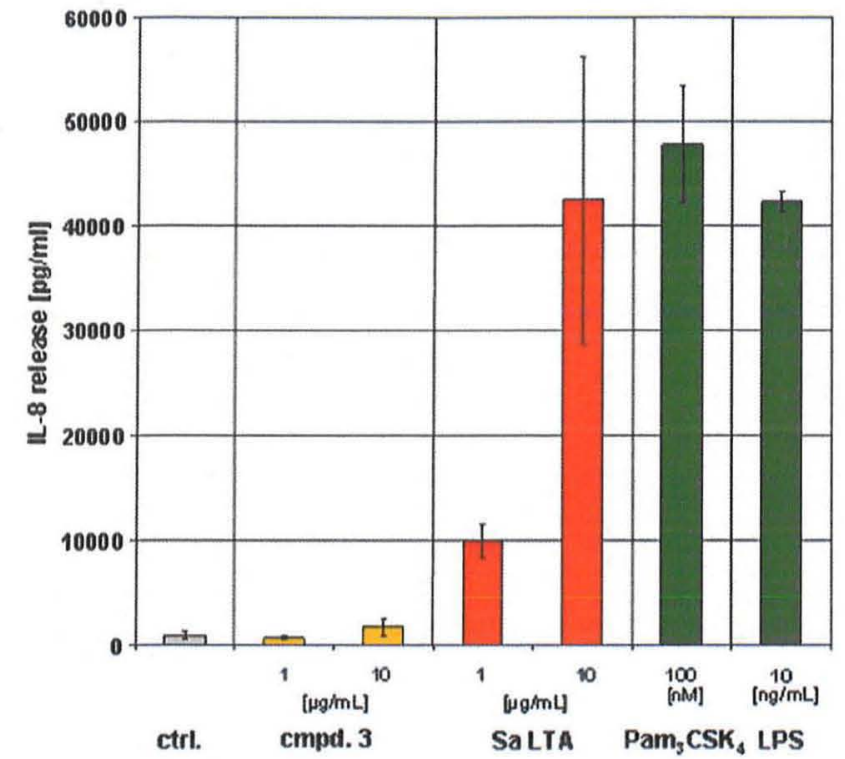

Fig. 1. Induction of IL-8 release in human MNC by synthetic compound 3. As a control, the cells were stimulated also with a native preparation of LTA of a lgt-mutant of Staphylococcus aureus, LPS derived from Salmonella friedenau, and synthetic Pam ${ }_{3}$ C-SK After incubation for $16 \mathrm{~h}$ the release of $\mathrm{IL}-8$ into the culture supernatant was determined by ELISA. Each result represents the mean \pm SD of duplicate cultures.

response via the innate immune system. Hence, further studies are required to elucidate the influence of the LTA repeating unit on the host's immune defence system.

\section{Experimental section}

\subsection{General}

Solvents were dried according to standard procedures. NMR spectroscopic measurements were performed at $22^{\circ} \mathrm{C}$ with Bruker DRX600, Bruker Avance 600 cryo, Bruker 400 Avance, Varian Mercury 300 and Bruker AC250 instruments. TMS of the resonances of the deuterated solvents were used as an internal standard. $\mathrm{CDCl}_{3}(\delta$ $7.24 \mathrm{ppm}$ ) was used as an external standard; $85 \%$ of phosphoric acid was used as an external standard for ${ }^{31} \mathrm{P}$ spectra. IR was recorded on a Bruker ALPHA instrument equipped with an ATR single reflection diamond. MALDI mass spectra were recorded with a Kratos Kompact Maldi II spectrometer, 2,5-dihydroxybenzoic acid (DHB) or pnitroaniline and Nal were used as matrices for positive measurements, and trilydroxyacetophenone (THAP) was used as matrix for negative mode measurements. Optical rotation was recorded with a Perkin-Elmer polarimeter $241 / \mathrm{MS}$ in a $1-\mathrm{dm}$ cell at $22^{\circ} \mathrm{C}$. Thin layer chromatography (TLC) was performed on E. Merck Silica Gel 60 $\mathrm{F}_{254}$ plastic plates. The compounds were visualized by a treatment with a solution of $\left(\mathrm{NH}_{4}\right)_{6} \mathrm{Mo}_{7} \mathrm{O}_{24} \cdot 4 \mathrm{H}_{2} \mathrm{O}(20 \mathrm{~g})$ and $\mathrm{Ce}\left(\mathrm{SO}_{4}\right)_{2}(0.4 \mathrm{~g})$ in $10 \% \mathrm{H}_{2} \mathrm{SO}_{4}(400 \mathrm{~mL})$. Flash chromatography was performed on J. T. Baker Silica Gel $60(0.040-0.063 \mathrm{~mm})$ at a pressure of 0.3 bar.

4.1.1. Phenyl 3,4,6-tri-O-acetyl-2-azido-2-deoxy-1-thio- $\alpha, \beta$-D-galactopyranoside (12). To a solution of compound $\mathbf{1 1}^{15}(12.91 \mathrm{~g}$, $34.6 \mathrm{mmol})$ in $\mathrm{CH}_{2} \mathrm{Cl}_{2}(100 \mathrm{~mL})$, thiophenol $(4.3 \mathrm{~mL} ; 41.5 \mathrm{mmol}$, 1.2 equiv) was added and the mixture cooled with ice bath, then $\mathrm{BF}_{3} \cdot \mathrm{OEt}_{2}$ (1.5 equiv) was added dropwise and the reaction mixture stirred for 3 days at room temperature. The reaction mixture was neutralized with saturated sodium bicarbonate solution and washed with water, dried with sodium sulfate and the solvent was removed in vacuo. The product was purified by flash chromatography (petroleum
ether/EtOAc, 2:1) to give $\mathbf{1 2}(12.3 \mathrm{~g}, 84 \%)$. The physical clata were in accordance with those reported in the literature. ${ }^{16}$

4.1.2. Phenyl 2-azido-4,6-0-benzylidene-1-thio- $\alpha$ - and - $\beta$-D-galactopyranoside (13 $\alpha$ and 13 $\beta$ ). Compound 12 (12.00 g, $28.34 \mathrm{mmol}$ ) was dissolved in $\mathrm{MeOH}(250 \mathrm{~mL})$ and $4 \mathrm{~mL}$ of a $0.2 \mathrm{M} \mathrm{NaOMe}$ $(\mathrm{MeOH})$ solution was added. The reaction mixture was stirred for $1 \mathrm{~h}$ and after this time neutralized with ionic exchange resin (IR120H ${ }^{+}$ form) and the solvent evaporated in vacuo. The intermediate product was dried for $1 \mathrm{~h}$ in high vacuo and then redissolved in DMF (100 mL). Benzaldehyde dimethyl acetal $(6.4 \mathrm{~mL}, 42.52 \mathrm{mmol})$ was added to the solution followed by addition of $p$-TsOH $(0.488 \mathrm{~g}$ $2.83 \mathrm{mmol}$ ). The reaction mixture was stirred overnight at $40{ }^{\circ} \mathrm{C}$; after this time the mixture was poured into water and extracted with EtOAc twice. The organic extracts were combined, washed with water and brine, dried with sodium sulfate and the solvent was evaporated in vacuo. The product was purified by flash chromatography (petroleum ether/EtOAc, $3: 1 \rightarrow 1: 1$ ) and the anomeric mixture separated to give $13 \alpha$ and $\mathbf{1 3} \beta$ (9:7) (10.12 g, 93\%). TLC (petroleum ether/EtOAc, 2:1) $R_{f}=0.64 \alpha$-isomer, $0.15 \beta$-isomer. The physical data were in agreement with those reported in the literature. ${ }^{23}$

4.1.3. Phenyl 2-azido-3-O-benzyl-4,6-0-benzylidene-1-thio- $\alpha$-D-galactopyranoside $(14 \alpha)$. To a solution of $13 \alpha(4.62 \mathrm{~g}, 12.0 \mathrm{mmol})$ in DMF (60 $\mathrm{mL}), \mathrm{NaH} 60 \%\left(0.71 \mathrm{~g}, 1.5\right.$ equiv) was added at $0{ }^{\circ} \mathrm{C}$ and the reaction mixture stirred for $30 \mathrm{~min}$ at that temperature. Benzyl bromide (1.72 $\mathrm{mL}, 1.2$ equiv) was then added and the reaction mixture stirred for another $3 \mathrm{~h}$. Methanol was added to quench the reaction and the clear solution was poured in water and extracted twice with EtOAc. The organic phase was washed with water, dried over $\mathrm{MgSO}_{4}$ and the solvent evaporated in vacuo. Flash chromatography (petroleum ether/EtOAc, 13:1) yielded $14 \alpha(5.0 \mathrm{~g}, 88 \%)$ as a colourless syrup. TLC (petroleum ether/EtOAc, 8:1) $R_{f}=0.45 . \nu_{\max }($ ATR $) 2107 \mathrm{~cm}^{-1} ;{ }^{1} \mathrm{H}$ NMR $\left(250 \mathrm{MHz}, \mathrm{CDCl}_{3}\right) \delta 7.60-7.20(\mathrm{~m}, 15 \mathrm{H}, \mathrm{Pl}), 5.80\left(\mathrm{~d}, 1 \mathrm{H}, J_{1,2}=5.3 \mathrm{~Hz}\right)$, $5.50(\mathrm{~s}, 1 \mathrm{H}, \mathrm{CHPh}), 4.80\left(\mathrm{~d}, 2 \mathrm{H}, \mathrm{CH}_{2} \mathrm{Ph}\right), 4.50\left(\mathrm{dd}, 1 \mathrm{H}, J_{2,1}=5.3 \mathrm{~Hz}\right.$, $\left.J_{2,3}=10.6 \mathrm{~Hz}\right), 4.20(\mathrm{~m}, 4 \mathrm{H}, 4-\mathrm{H}, 5-\mathrm{H}, 6-\mathrm{H}), 3.90\left(\mathrm{dd}, 1 \mathrm{H}, J_{3,2}=10.6 \mathrm{~Hz}\right.$, $\left.J_{3,4}=3.4 \mathrm{~Hz}, 3-\mathrm{H}\right) \cdot{ }^{13} \mathrm{CNMR}\left(125 \mathrm{MHz}, \mathrm{CDCl}_{3}\right) \delta 137.8,137.7,134.0,131.3$, $129.3,129.3,128.7,128.4,128.2,128.0,127.5,126.4,101.2,87.8,76.6$, 73.1, 71.6, 69.6, 64.0, 59.5. MALDI-MS (positive mode, matrix DHB, THF): $[\mathrm{M}+\mathrm{Na}]^{+} \mathrm{m} / \mathrm{z} 498.2$, found 498.1. $\mathrm{C}_{26} \mathrm{H}_{25} \mathrm{~N}_{3} \mathrm{O}_{4} \mathrm{~S}$ (475.56), calcd: C 65.67, H 5.30, N 8.84, found: C 65.81, H 5.18, N 8.72.

4.1.4. Phenyl 2-azido-3-O-benzyl-2-deoxy-1-thio- $\alpha$-D-galactopyranoside (15 $\alpha$ ). To a solution of $14 \alpha(4.4 \mathrm{~g}, 9.25 \mathrm{mmol})$ in $\mathrm{CH}_{2} \mathrm{Cl}_{2} /$ $\mathrm{MeOH}(1: 1,80 \mathrm{~mL})$, CSA (0.43 g, 0.2 equiv) was added and the reaction mixture stirred for $24 \mathrm{~h}$. The mixture was diluted with $\mathrm{CH}_{2} \mathrm{Cl}_{2}$ and washed with $\mathrm{NaHCO}_{3}$ saturated solution, the organic phase was dried over sodium sulfate and the solvent evaporated in vacuo. Flash chromatography (petroleum ether/EtOAc, 1:1) yielded $\mathbf{1 5} \alpha(2.73 \mathrm{~g}, 77 \%)$ as a colourless syrup. TLC (petroleum ether/EtOAc, 1:1) $R_{f}=0.38 .[\alpha]_{\mathrm{D}}^{22}+15.8\left(\mathrm{c} 1, \mathrm{CHCl}_{3}\right) .{ }^{1} \mathrm{H}$ NMR $\left(250 \mathrm{MHz}, \mathrm{CDCl}_{3}\right)$ $\delta 7.20(\mathrm{~m}, 10 \mathrm{H}, \mathrm{Ph}), 5.65\left(\mathrm{~d}, 1 \mathrm{H}, J_{1,2}=5.4 \mathrm{~Hz}, 1-\mathrm{H}\right), 4.70(2 \times \mathrm{d}, 2 \mathrm{H}$, $\left.\mathrm{CH}_{2} \mathrm{Ph}\right), 4.30(\mathrm{~m}, 2 \mathrm{H}, 2-\mathrm{H}, 5-\mathrm{H}), 4.15\left(\mathrm{~m}, 1 \mathrm{H}, \mathrm{G}^{\prime}-\mathrm{H}\right), 3.90(\mathrm{~m}, 1 \mathrm{H}, 6-\mathrm{H})$, 3.80 ( $\mathrm{m}, 2 \mathrm{H}, 3-\mathrm{H}, 4-\mathrm{H}$ ). MALDI-MS (positive mode, matrix DHB, THF): $[\mathrm{M}+\mathrm{Na}]^{+} \mathrm{m} / \mathrm{z} 410.1$, found $410.2 . \mathrm{C}_{19} \mathrm{H}_{21} \mathrm{~N}_{3} \mathrm{O}_{4} \mathrm{~S}$ (387.45), calcd: C 58.90, H 5.46, N 10.85, found: C 59.12, H 5.55, N 10.73.

4.1.5. Phenyl 2-azido-3-0-benzyl-6-0-tert-butyl-diphenylsilyl-2deoxy-1-thio- $\alpha$ - and - $\beta$-D-galactopyranoside ( $\boldsymbol{\beta} \alpha$ and $\boldsymbol{8} \beta$ ). To a solution of $\mathbf{1 5} \alpha$ (2.23 g, $5.76 \mathrm{mmol})$ in DMF (20 mL), imidazole $(0.705 \mathrm{~g}$, 1.8 equiv) and TBDPS- $\mathrm{Cl}(1.8 \mathrm{~mL}, 1.2$ equiv $)$ were added. The reaction mixture was stirred for $2 \mathrm{~h}$ and then poured in to water and extracted twice with EtOAc. The organic phase was washed with water, dried over sodium sulfate and the solvent was removed in vacuo. Flash chromatography (petroleum ether/EtOAc, 6:1) yielded $8 \alpha$ (3.4 g, 94\%). TLC (petroleum ether/EtOAc, 5:1) $R_{f}=0.45$. $[\alpha]_{\mathrm{D}}^{22}+12.3(c 1$, 
$\left.\mathrm{CHCl}_{3}\right), \nu_{\max }(\mathrm{ATR}) 3474(\mathrm{br}), 2109 \mathrm{~cm}^{-1} ;{ }^{1} \mathrm{H}$ NMR $\left(250 \mathrm{MHz}, \mathrm{CDCl}_{3}\right.$ ) $\delta 7.40(\mathrm{~m}, 20 \mathrm{H}, \mathrm{Ph}), 5.60\left(\mathrm{~d}, 1 \mathrm{H}, J_{1,2}=5.1 \mathrm{~Hz}, 1-\mathrm{H}\right), 4.75\left(\mathrm{~d}, 2 \mathrm{H}, \mathrm{CH}_{2} \mathrm{Ph}\right)$, $4.33(\mathrm{~m}, 2 \mathrm{H}, 2-\mathrm{H}, 5-\mathrm{H}), 4.20\left(\mathrm{~m}, 1 \mathrm{H}, \mathrm{6}^{\prime}-\mathrm{H}\right), 3.90(\mathrm{~m}, 2 \mathrm{H}, 4-\mathrm{H}, 6-\mathrm{H}), 3.70$ $\left(\mathrm{dd}, 1 \mathrm{H}, J_{3,4}=3.0 \mathrm{~Hz}, J_{3,2}=10.0 \mathrm{~Hz}, 3-\mathrm{H}\right), 1.05\left(\mathrm{~s}, 9 \mathrm{H}, \mathrm{C}\left(\mathrm{CH}_{3}\right)_{3}\right)$.

Via the same route was obtained $8 \beta$ from 13 $\beta$ : $\nu_{\max }$ (ATR) 3450 (br), $2109 \mathrm{~cm}^{-1}$; ${ }^{1} \mathrm{H}$ NMR $\left(250 \mathrm{MHz}, \mathrm{CDCl}_{3}\right) \delta 7.40(\mathrm{~m}, 20 \mathrm{H}, \mathrm{Ph})$, $4.70\left(\mathrm{~s}, 2 \mathrm{H}, \mathrm{CH}_{2} \mathrm{Ph}\right), 4.35$ (d, $\left.1 \mathrm{H}, J_{1,2}=10.2 \mathrm{~Hz}, 1-\mathrm{H}\right), 4.15\left(\mathrm{~m}, 1 \mathrm{H}, 6^{\prime}-\right.$ H), $3.90(\mathrm{~m}, 2 \mathrm{H}, 2-\mathrm{H}, 5-\mathrm{H}), 3.65\left(\mathrm{t}, 1 \mathrm{H},{ }^{3} \mathrm{~J}=9.8 \mathrm{~Hz}, 6-\mathrm{H}\right), 3.40(\mathrm{~m}$, $2 \mathrm{H}, 3-\mathrm{H}, 4-\mathrm{H}), 1.05\left(\mathrm{~s}, 9 \mathrm{H}, \mathrm{C}\left(\mathrm{CH}_{3}\right)_{3}\right)$. MALDI-MS (positive mode, matrix DHB, THF): $[\mathrm{M}+\mathrm{Na}]^{+} \mathrm{m} / \mathrm{z}$ 632.3, found 632.2. $\mathrm{C}_{35} \mathrm{H}_{39} \mathrm{~N}_{3} \mathrm{O}_{4} \mathrm{SSi}$ (635.85), calcd: $\mathrm{C} 68.93, \mathrm{H} 6.45, \mathrm{~N} 6.89$, found: $\mathrm{C}$ 69.15, H 6.58, N 6.81.

4.1.6. Phenyl 3-0-acetyl-2-azido-4,6-0-benzylidene-2-deoxy-1-thio$\alpha$ - and - $\beta$-D-galactopyranoside (16 $\alpha$ and 16/). Compound $13 \alpha$ $(5.5 \mathrm{~g}, 14.3 \mathrm{mmol})$ was dissolved in pyridine $/ \mathrm{Ac}_{2} \mathrm{O}(2: 1,150 \mathrm{~mL})$. The reaction mixture was stirred for $2 \mathrm{~h}$ and the solvent removed in vacuo. The residue was dissolved in EtOAc and washed with a $1 \mathrm{M}$ $\mathrm{HCl}$ solution and water, dried with $\mathrm{MgSO}_{4}$ and the solvent was removed in vacuo. Flash chromatography (petroleum ether/EtOAc, $3: 1$ ) yielded $16 \alpha(5.90 \mathrm{~g}, 97 \%)$ as a colourless syrup. TLC (petroleum ether/EtOAc, 3:1) $R_{f}=0.38$. $\left.[\alpha]\right]_{\mathrm{D}}^{22}+22.3\left(\right.$ ( $\left.1, \mathrm{CHCl}_{3}\right) .{ }^{1} \mathrm{H}$ NMR $\left(250 \mathrm{MHz}, \mathrm{CDCl}_{3}\right) \delta 7.20(\mathrm{~m}, 10 \mathrm{H}, \mathrm{Ph}), 5.80\left(\mathrm{~d}, 1 \mathrm{H}, J_{1,2}=5.3 \mathrm{~Hz}, 1-\mathrm{H}\right)$, $5.55(\mathrm{~s}, 1 \mathrm{H}, \mathrm{PhCH}), 5.15\left(\mathrm{dd}, 1 \mathrm{H}, J_{3,4}=3.4 \mathrm{~Hz}, J_{3,2}=11.1 \mathrm{~Hz}, 3-\mathrm{H}\right), 4.55$ $\left(\mathrm{m}, 2 \mathrm{H}, 4-\mathrm{H}, 6^{\prime}-\mathrm{H}\right), 4.15(\mathrm{~m}, 3 \mathrm{H}, 2-\mathrm{H}, 5-\mathrm{H}, 6-\mathrm{H}), 2.15\left(\mathrm{~s}, 3 \mathrm{H}, \mathrm{CH}_{3} \mathrm{OC}\right)$. MALDI-MS (positive mode, matrix DHB, THF): $[\mathrm{M}+\mathrm{Na}]^{+} \mathrm{m} / \mathrm{z} 450.1$, found 450.2. $\mathrm{C}_{21} \mathrm{H}_{21} \mathrm{~N}_{3} \mathrm{O}_{3} \mathrm{~S}$ (427.47), calcd: C 59.00, H 4.95, N 9.83 , found: C 58.84, H 5.02, N 9.93 .

The same procedure was employed for the transformation of $13 \beta$ into 16 $\beta$ : $[\alpha]_{\mathrm{D}^{22}}-16.0\left(\mathrm{c} 1, \mathrm{CHCl}_{3}\right) .{ }^{1} \mathrm{H}$ NMR $\left(500 \mathrm{MHz}, \mathrm{CDCl}_{3}\right)$ $\delta 7.66(\mathrm{~m}, 2 \mathrm{H}, \mathrm{Ar}), 7.36-7.16(\mathrm{~m}, 8 \mathrm{H}, \mathrm{Ar}), 5.42(\mathrm{~s}, 1 \mathrm{H}, \mathrm{PhCH}), 4.74(\mathrm{dd}$, $1 \mathrm{H}, J=3.3,10.3 \mathrm{~Hz}, 3-\mathrm{H}), 4.43$ (d, $1 \mathrm{H}, J=9.9 \mathrm{~Hz}, 1-\mathrm{H}), 4.32$ (dd, $1 \mathrm{H}$, $J=1.6,12.4 \mathrm{~Hz}, 6-\mathrm{H}), 4.27(\mathrm{dd}, 1 \mathrm{H}, J=0.7,3.3 \mathrm{~Hz}, 4-\mathrm{H}), 3.95(\mathrm{dd}, 1 \mathrm{H}$, $\left.J=1.6,12.4 \mathrm{~Hz}, 6^{\prime}-\mathrm{H}\right), 3.79(\mathrm{dd}, 1 \mathrm{H}, J=9.9,10.3 \mathrm{~Hz}, 2-\mathrm{H}), 3.49(\mathrm{~m}, 1 \mathrm{H}$, 5-H), 2.03 (s, 3H, Ac). ${ }^{13} \mathrm{C}$ NMR (125 MHz, $\left.\mathrm{CDCl}_{3}\right) \delta 170.4(\mathrm{C}=\mathrm{O})$, 137.5 (Ar), 134.3 (2C, Ar), 130.1 (Ar), $129.3(\mathrm{Ar}), 129.1$ (2C, Ar), 128.5 $(\mathrm{Ar}), 128.2(\mathrm{Ar}), 126.4(2 \mathrm{C}, \mathrm{Ar}), 101.0(\mathrm{PhCH}), 85.4(\mathrm{C}-1), 74.0(\mathrm{C}-3)$, 72.7 (C-4), 69.7 (C-5), 69.2 (C-6), 58.3 (C-2), 21.0 (Ar). HRMS: $\left.{ }^{\mathrm{M}+\mathrm{Na}}\right]^{+} \mathrm{m} / \mathrm{z}$ 450.1100; found 450.1024 .

4.1.7. Phenyl 3-0-acetyl-2-azido-4-0-benzyl-2-deoxy-1-thio- $\alpha$ - and $-\beta-D$-galactopyranoside (17 $\alpha$ and $17 \beta$ ). Compound $16 \alpha$ was dissolved in dry $\mathrm{CH}_{2} \mathrm{Cl}_{2}(60 \mathrm{~mL})$, cooled to $0{ }^{\circ} \mathrm{C}$ and $1 \mathrm{M}$ borane tetrahydrofuran complex solution in THF (138 mL, 10 equiv) was added. After 5 min dibutylboryl triflate solution ( $13.8 \mathrm{~mL}, 1$ equiv, $1 \mathrm{M}$ in THF) was added dropwise. The reaction was stirred for $1 \mathrm{~h}$ at $0{ }^{\circ} \mathrm{C}$ and neutralized with $\mathrm{Et}_{3} \mathrm{~N}$ : excess borane was quenched with $\mathrm{MeOH}$. The solvent was removed in vacuo and the residue coevaporated several times with $\mathrm{MeOH}$. The product was purified by flash chromatography (petroleum ether/EtOAc, 3:1) to give $17 \alpha$ $(4.41 \mathrm{~g}, 74 \%)$ as a colourless syrup. TLC (petroleum ether/EtOAc, 3:1) $R_{f}=0.22 .[\alpha]_{D}^{22}+17.3\left(\right.$ c $\left.1, \mathrm{CHCl}_{3}\right) .{ }^{1} \mathrm{H}$ NMR $\left(250 \mathrm{MHz}, \mathrm{CDCl}_{3}\right) \delta 7.20$ $(\mathrm{m}, 10 \mathrm{H}, \mathrm{Ph}), 5.80\left(\mathrm{~d}, 1 \mathrm{H}, J_{1,2}=5.3 \mathrm{~Hz}, 1-\mathrm{H}\right), 4.80\left(\mathrm{dd}, 1 \mathrm{H}, J_{3,4}=3.0 \mathrm{~Hz}\right.$, $\left.J_{3,2}=10.3 \mathrm{~Hz}, 3-\mathrm{H}\right), 4.70\left(\mathrm{~d}, 1 \mathrm{H}, \mathrm{CH}_{2} \mathrm{Ph}\right), 4.50\left(\mathrm{~d}, 1 \mathrm{H}, \mathrm{CH}_{2} \mathrm{Ph}\right), 3.85(\mathrm{~m}$, $\left.3 \mathrm{H}, 4-\mathrm{H}, 5-\mathrm{H}, \mathrm{G}^{\prime}-\mathrm{H}\right), 3.55(\mathrm{~m}, 2 \mathrm{H}, 2-\mathrm{H}, 6-\mathrm{H}), 2.15\left(\mathrm{~s}, 3 \mathrm{H}, \mathrm{CH}_{3} \mathrm{OC}\right)$. MALDI-MS (positive mode, matrix DHB, THF): $[\mathrm{M}+\mathrm{Na}]^{+} \mathrm{m} / z$ 452.1, found 452.2. $\mathrm{C}_{21} \mathrm{H}_{23} \mathrm{~N}_{3} \mathrm{O}_{5} \mathrm{~S}$ (429.49), calcd: C 58.73, H 5.40, N 7.98, found: C 58.84, H 5.27, N 7.77 .

The same procedure was employed for the transformation of $16 \beta$ into $17 \beta$ that was immediately transformed into $18 \beta$ (see below).

4.1.8. Phenyl 3-O-acetyl-2-azido-4-O-benzyl-6-O-tert-butyl-diphenylsilyl-2-deoxy-1-thio- $\alpha$ - and $-\beta$-D-galactopyranoside $(18 \alpha$ and 18ß). Compound $17 \propto(3.2 \mathrm{~g}, 7.4 \mathrm{mmol})$ was dissolved in dry $\mathrm{CH}_{2} \mathrm{Cl}_{2}$ $(30 \mathrm{~mL})$, and imidazole $(0.921 \mathrm{~g}, 1.8$ equiv) and TBDPS $-\mathrm{Cl}(2.32 \mathrm{~mL}$,
1.2 equiv) were added. The reaction mixture was stirred for $1 \mathrm{~h}$ at room temperature and then quenched with $\mathrm{MeOH}$. The solvent was evaporated in vacuo. Flash chromatography (petroleum ether/ EtOAc, 8:1) yielded $\mathbf{1 8} \alpha(4.6 \mathrm{~g}, 92 \%$ ) as a colourless syrup. TLC (petroleum ether/EtOAc, 5:1) $R_{f}=0.61$. $[\alpha]_{D}^{22}+19.6\left(\right.$ c $\left.1, \mathrm{CHCl}_{3}\right)$. $\nu_{\max }(\mathrm{ATR}) 2110 \mathrm{~cm}^{-1} ;{ }^{1} \mathrm{H}$ NMR $\left(250 \mathrm{MHz}, \mathrm{CDCl}_{3}\right) \delta 7.20(\mathrm{~m}, 20 \mathrm{H})$, $5.45\left(\mathrm{~d}, 1 \mathrm{H}, J_{1,2}=5.6 \mathrm{~Hz}, 1-\mathrm{H}\right), 5.15\left(\mathrm{dd}, 1 \mathrm{H}, J_{3,2}=10.1 \mathrm{~Hz}, J_{3,4}=3.0 \mathrm{~Hz}\right.$, 3- $\mathrm{H}), 4.70\left(2 \times \mathrm{d}, 2 \mathrm{H}, \mathrm{CH}_{2} \mathrm{Ph}\right), 4.45(\mathrm{~m}, 2 \mathrm{H}, 4-\mathrm{H}, 5-\mathrm{H}), 4.25\left(\mathrm{~m}, 1 \mathrm{H}, 6^{\prime}-\right.$ $\mathrm{H}), 3.80\left(\mathrm{dd}, 1 \mathrm{H}, J_{6,5}=8.1 \mathrm{~Hz}, J_{\text {gem }}=10.1 \mathrm{~Hz}, 6-\mathrm{H}\right), 3.60(\mathrm{dd}, 1 \mathrm{H}$, $\left.J_{2,1}=5.8 \mathrm{~Hz}, J_{2,3}=10.0 \mathrm{~Hz}, 2-\mathrm{H}\right), 2.15\left(\mathrm{~s}, 3 \mathrm{H}, \mathrm{CH}_{3} \mathrm{CO}\right), 1.05(\mathrm{~s}, 9 \mathrm{H}, t-\mathrm{Bu})$.

The same procedure was employed for the transformation of $17 \beta$ into 18 $\beta$ : ${ }^{1} \mathrm{H}$ NMR $\left(250 \mathrm{MHz}, \mathrm{CDCl}_{3}\right) \delta 7.20(\mathrm{~m}, 20 \mathrm{H}), 4.85$ (dd, $\left.1 \mathrm{H}, J_{3,2}=10.2 \mathrm{~Hz}, J_{3,4}=2.9 \mathrm{~Hz}, 3-\mathrm{H}\right), 4.65\left(2 \times \mathrm{d}, 2 \mathrm{H}, \mathrm{CH}_{2} \mathrm{Ph}\right), 4.45$ (d, $\left.1 \mathrm{H}, J_{1,2}=9.8 \mathrm{~Hz}\right), 4.10\left(\mathrm{~m}, 1 \mathrm{H}, 6^{\prime}-\mathrm{H}\right), 3.85(\mathrm{~m}, 3 \mathrm{H}, 4-\mathrm{H}, 5-\mathrm{H}, 6-\mathrm{H}), 3.60$ $\left(\mathrm{t}, 1 \mathrm{H}, J_{2,1}=J_{2,3}=9.6 \mathrm{~Hz}, 2-\mathrm{H}\right), 2.15\left(\mathrm{~s}, 3 \mathrm{H}, \mathrm{CH}_{3} \mathrm{CO}\right), 1.05(\mathrm{~s}, 9 \mathrm{H}, t-\mathrm{Bu})$. MALDI-MS (positive mode, matrix DHB, THF): $[\mathrm{M}+\mathrm{Na}]^{+} \mathrm{m} / z$ 690.2, found 690.1. $\mathrm{C}_{37} \mathrm{H}_{41} \mathrm{~N}_{3} \mathrm{O}_{5} \mathrm{SSi}$ (575.73), calcd: C 66.54, H 6.19, N 6.29, found: C 66.38, H 6.27, N 6.42.

4.1.9. 3-O-Acetyl-2-azido-4-O-benzyl-6-O-tert-butyl-diphenylsilyl2 -deoxy-1-thio- $\alpha, \beta$-D-galactopyranose (19). A solution of 18 ( $\alpha$ - or $\beta$-anomer) $(3.50 \mathrm{~g}, 5.24 \mathrm{mmol})$ in acetone $(80 \mathrm{~mL})$ was cooled to $15^{\circ} \mathrm{C}$ and NBS ( $1.31 \mathrm{~g}, 1.4$ equiv) was added and the reaction stirred for $15 \mathrm{~min}$ in the dark. TLC (petroleum ether/EtOAc, 5:1) showed that the reaction was finished. The reaction mixture was quenched with sodium bicarbonate, diluted and extracted with ethyl acetate. The organic phase was washed with brine and dried over $\mathrm{MgSO}_{4}$. Flash chromatography (petroleum ether/EtOAc, 6:1) yielded 19 $(2.60 \mathrm{~g}, 86 \%)$ as a colourless syrup. TLC (petroleum ether/EtOAC, $5: 1) R_{f}=0.28 .[\alpha .]_{\mathrm{D}}^{22}+25.2\left(\mathrm{c} 1, \mathrm{CHCl}_{3}\right) .{ }^{1} \mathrm{H}$ NMR $\left(250 \mathrm{MHz}, \mathrm{CDCl}_{3}\right)$ $\delta 7.70-7.20(\mathrm{~m}, 30 \mathrm{H}, \alpha / \beta-\mathrm{Pl}), 5.40\left(\mathrm{dd}, 1 \mathrm{H}, J_{3,2}=11.0 \mathrm{~Hz}, J_{3,4}=3.0 \mathrm{~Hz}\right.$, $3 \alpha-\mathrm{H}$ ), 5.30 (t, $\left.1 \mathrm{H}, J_{1,2}=J_{1, \mathrm{OH}}=3.0 \mathrm{~Hz}, 1 \alpha-\mathrm{H}\right), 4.75$ (dd, $1 \mathrm{H}$, $\left.J_{3,2}=10.8 \mathrm{~Hz}, J_{3,4}=3.1 \mathrm{~Hz}, 3 \beta-\mathrm{H}\right), 4.65\left(\mathrm{~m}, 4 \mathrm{H}, \alpha / \beta-\mathrm{CH}_{2} \mathrm{Pl}\right.$ ), 4.50 (dd, $\left.1 \mathrm{H}, J_{4,3}=6.0 \mathrm{~Hz}, J_{4,5}=7.9 \mathrm{~Hz}, 4 \alpha-\mathrm{H}\right), 4.25-4.00(\mathrm{~m}, 4 \mathrm{H}, 1 \beta-\mathrm{H}, 5 \alpha-\mathrm{H}$, $\left.6^{\prime} \alpha-\mathrm{H}, 6^{\prime} \beta-\mathrm{H}\right), 3.95-3.65\left(\mathrm{~m}, 5 \mathrm{H}, 2 \alpha-\mathrm{H}, 4 \beta-\mathrm{H}, 5 \beta-\mathrm{H}, 6^{\prime} \alpha-\mathrm{H}, 6^{\prime} \beta-\mathrm{H}\right)$, $3.55\left(\mathrm{dd}, 1 \mathrm{H}, J_{2,1}=8.0 \mathrm{~Hz}, J_{2,3}=9.0 \mathrm{~Hz}, 2 \beta-\mathrm{H}\right), 3.30(\mathrm{~d}, 1 \mathrm{H}, J=6.0 \mathrm{~Hz}, \beta-$ $\mathrm{OH}), 2.85(\mathrm{~d}, 1 \mathrm{H}, J=3.1 \mathrm{~Hz}, \alpha-\mathrm{OH}), 2.05\left(2 \mathrm{~s}, 6 \mathrm{H}, \alpha / \beta-\mathrm{CH}_{3} \mathrm{CO}\right), 1.05(\mathrm{~s}$, $18 \mathrm{H}, t-\mathrm{Bu}$ ). MALDI-MS (positive mode, matrix DHB, THF): [M+Na $]^{+}$ $\mathrm{m} / \mathrm{z} 598.2$, found 598.1. $\mathrm{C}_{31} \mathrm{H}_{37} \mathrm{~N}_{3} \mathrm{O}_{6} \mathrm{Si}$ (575.73), calcd: C 64.67, $\mathrm{H}$ 6.48 , N 7.30, found: C 64.72, H 6.49, N 7.42.

4.1.10. O-(3-0-acetyl-2-azido-4-O-benzyl-6-O-tert-butyl-diphenylsilyl-2-deoxy- $\alpha, \beta-D$-galactopyranosyl) trichloroacetimidate (7). To a solution of $19(2.5 \mathrm{~g}, 4.34 \mathrm{mmol})$ in dry $\mathrm{CH}_{2} \mathrm{Cl}_{2}(50 \mathrm{~mL})$, trichloroacetonitrile ( $8.7 \mathrm{~mL}, 20$ equiv) and $\mathrm{DBU}(0.065 \mathrm{~mL}, 0.1$ equiv) were added. The reaction mixture was stirred for $2 \mathrm{~h}$ and the solvent evaporated in vacuo; the product was purified by fast flash chromatography (petroleum ether/EtOAc, 5:1) yielding 7 (2.85 g, $91 \%$ ) as colourless syrup. TLC (petroleum ether/EtOAc, 5:1) $R_{f}=0.52$. ${ }^{1} \mathrm{H}$ NMR $\left(250 \mathrm{MHz}, \mathrm{CDCl}_{3}\right) \beta$-isomer: $\delta 8.70(\mathrm{~s}, 1 \mathrm{H}, \mathrm{NH}), 7.40(\mathrm{~m}, 15 \mathrm{H}$, $\mathrm{Ph}), 5.65\left(\mathrm{~d}, 1 \mathrm{H}, J_{1,2}=8.4 \mathrm{~Hz}, 1-\mathrm{H}\right), 4.85\left(\mathrm{dd}, 1 \mathrm{H}, J_{3,2}=10.7 \mathrm{~Hz}\right.$, $\left.\mathrm{J}_{3,4}=3.0 \mathrm{~Hz}, 3-\mathrm{H}\right), 4.60\left(\mathrm{~d}, 2 \mathrm{H}, \mathrm{CH}_{2} \mathrm{Ph}\right), 4.10\left(\mathrm{~m}, 2 \mathrm{H}, 5-\mathrm{H}, 6^{\prime}-\mathrm{H}\right), 3.80$ $(\mathrm{m}, 3 \mathrm{H}, 2-\mathrm{H}, 4-\mathrm{H}, 6-\mathrm{H}), 2.15\left(\mathrm{~s}, 3 \mathrm{H}, \mathrm{CH}_{3} \mathrm{CO}\right), 1.05(\mathrm{~s}, 9 \mathrm{H}, t-\mathrm{Bu})$. MALDIMS (positive mode, matrix DHB, THF): $[\mathrm{M}+\mathrm{Na}]^{+} \mathrm{m} / \mathrm{z} 741.2$, found 741.3 and 598.0 (imidate loss). $\mathrm{C}_{33} \mathrm{H}_{37} \mathrm{Cl}_{3} \mathrm{~N}_{4} \mathrm{O}_{6} \mathrm{Si}$ (720.11), calcd: $\mathrm{C}$ 55.04, H 4.18, N 7.78, found: C 54.89, H 4.46, N 7.83 .

4.1.11. Phenyl (2-azido-3-0-benzoyl-4-phthalimido-2,4,6-trideoxy- $\alpha$ D-galactopyranosyl)-(1-4)-2-azido-3-0-benzyl-6-0-tert-butyl-diphenylsilyl-2-deoxy-1-thio- $\alpha$-D-galactopyranoside $(20 \alpha)$. Donor 9 $(1.764 \mathrm{~g}, 3.11 \mathrm{mmol})$ and acceptor $8 \alpha(2.081 \mathrm{~g}, 3.33 \mathrm{mmol})$ were coevaporated three times with toluene and dried overnight together with $4 \AA \mathrm{MS} . \mathrm{CH}_{2} \mathrm{Cl}_{2}(30 \mathrm{~mL})$ was added and the mixture stirred for $1 \mathrm{~h}$ at room temperature before it was cooled to $0{ }^{\circ} \mathrm{C}$ and TMSOTf ( $56 \mu \mathrm{L}, 0.1$ equiv) added by syringe. After $30 \mathrm{~min}$ the reaction was quenched by the addition of $\mathrm{Et}_{3} \mathrm{~N}$, concentrated in 
vacuo and purified by flash chromatography (petroleum ether) EtOAc $5: 1$ to $2: 1$ ) to give disaccharide $\mathbf{2 0} \alpha$ as a white foam containing inseparable impurities of amide and hydrolyzed donor, which was successfully removed in the following step. $\nu_{\max }($ ATR $)$ 2107, $1719 \mathrm{~cm}^{-1} ;{ }^{1} \mathrm{H}$ NMR $\left(400 \mathrm{MHz}, \mathrm{CDCl}_{3}\right)$ o $7.80-7.00(\mathrm{~m}, 29 \mathrm{H}, \mathrm{Ar}), 5.75$ (dd, $1 \mathrm{H}, J=6.6,11.2 \mathrm{~Hz}, 3-\mathrm{H}), 5.50$ (d, $1 \mathrm{H}, J=5.5 \mathrm{~Hz}, 1 \mathrm{c}-\mathrm{H}), 5.39$ (d, $1 \mathrm{H}, J=4.0 \mathrm{~Hz}, 1 \mathrm{~d}-\mathrm{H}$ ), 5.01 (dd, $1 \mathrm{H}$ $J=3.8,6.7 \mathrm{~Hz}, 4 \mathrm{~d}-\mathrm{H}), 4.84-4.75(\mathrm{~m}, 3 \mathrm{H}, 5 \mathrm{~d}-\mathrm{H}, \mathrm{Bn}), 4.71(\mathrm{dd}, 1 \mathrm{H}$ $J=4.0,11.3 \mathrm{~Hz}, 2 \mathrm{~d}-\mathrm{H}), 4.37$ (d, $1 \mathrm{H}, J=2.6 \mathrm{~Hz}, 4 \mathrm{c}-\mathrm{H}), 4.33$ (dd, $1 \mathrm{H}$ $J=5.5,10.7 \mathrm{~Hz}, 2 \mathrm{c}-\mathrm{H}), 4.14(\mathrm{~m}, 2 \mathrm{H}, 6 \mathrm{c}-\mathrm{H}, 5 \mathrm{c}-\mathrm{H}), 3.62(\mathrm{dd}, 1 \mathrm{H}, J=2.6$, $10.7 \mathrm{~Hz}, 3 \mathrm{c}-\mathrm{H}), 3.58(\mathrm{~m}, 1 \mathrm{H}, 6 \mathrm{c}-\mathrm{H}), 1.03(\mathrm{~s}, 9 \mathrm{H}, t-\mathrm{Bu}), 0.74(\mathrm{~d}, 3 \mathrm{H}$, $J=6.4 \mathrm{~Hz}, 6 \mathrm{~d}-\mathrm{H}) .{ }^{13} \mathrm{C}$ NMR $\left(101 \mathrm{MHz}, \mathrm{CDCl}_{3}\right) \delta 168.8,165.1$, 137.5-123.5 (24C, Ar), 99.5, 87.8, 77.4, 73.3, 72.5, 71.5, 69.3, 64.2. $60.8,60.6,59.6,52.4,27.1,19.4,16.4$. HRMS $[\mathrm{M}+\mathrm{Na}]^{+} \mathrm{m} / \mathrm{z}$ 1052.3443, found 1052.3405 .

4.1.12. Phenyl (2-azido-4-benzyloxycarbonylamino-2,4,6-trideoxy- $\alpha$ D-galactopyranosyl)-(1-4)-2-azido-3-0-benzyl-6-0-tert-butyl-diphenylsilyl-2-deoxy-1-thio- $\alpha$ - and - $\beta-D$-galactopyranoside (21 $\alpha$ and $21 \beta)$. Disaccharide $20 \alpha$ was dissolved in $t-\mathrm{BuOH}(25 \mathrm{~mL})$ and 5 drops of MeONa solution was added to remove the benzoyl protecting group. After $2 \mathrm{~h}$ at room temperature ethylenediamine $(8.5 \mathrm{~mL}$ ) was added and the reaction was refluxed for $1 \mathrm{~h}$ followed by concentration on silica gel, filtration through silica gel and concentration of the fractions containing the intermediate amine. The amine was dissolved in a THF/water mixture $(32 \mathrm{~mL}, 4: 1)$ containing $\mathrm{NaHCO}_{3}$ (3 equiv). $\mathrm{Z}-\mathrm{Cl}(0.27 \mathrm{~mL}, 1.5$ equiv) was added and the reaction followed by TLC (EtOAc); when all starting material was consumed the reaction was diluted by EtOAc, washed with $\mathrm{HCl}(1 \mathrm{M})$, brine, dried $\left(\mathrm{MgSO}_{4}\right)$ and concentrated in vacuo. Flash chromatography (petroleum ether/EtOAc 1:7 to 1:4) gave $\mathbf{2 1} \alpha$ (two steps, $92 \%$ overall yield) as a colourless syrup. Compound $21 \alpha:[\alpha]_{\mathrm{D}}^{22}+30.8\left(\right.$ ( $\left.1, \mathrm{CHCl}_{3}\right) ; \nu_{\max }(\mathrm{ATR}) 2108,1698 \mathrm{~cm}^{-1} ;{ }^{1} \mathrm{H}$ NMR (600 MHz, CDCl $\left.)_{3}\right)$ 7.67-7.10 (m, 25H, Ar), $5.52(\mathrm{~d}, 1 \mathrm{H}, J=5.3 \mathrm{~Hz}$, $1 \mathrm{c}-\mathrm{H}), 5.17(\mathrm{~d}, 1 \mathrm{H}, J=3.8 \mathrm{~Hz}, 1 \mathrm{~d}-\mathrm{H}), 5.14\left(\mathrm{~d}, 1 \mathrm{H}, J=11.8 \mathrm{~Hz}, \mathrm{CH}_{2}, \mathrm{Z}\right)$, $5.12\left(\mathrm{~d}, 1 \mathrm{H}, J=11.8 \mathrm{~Hz}, \mathrm{CH}_{2}, \mathrm{Z}\right), 5.05(\mathrm{~d}, 1 \mathrm{H}, J=8 \mathrm{~Hz}, \mathrm{NH} \mathrm{Z}), 4.82(\mathrm{~s}$, $2 \mathrm{H}, \mathrm{Bn}), 4.59(\mathrm{~m}, 1 \mathrm{H}, 5 \mathrm{~d}-\mathrm{H}), 4.27(\mathrm{~d}, 1 \mathrm{H}, J=2.3 \mathrm{~Hz}, 4 \mathrm{c}-\mathrm{H}), 4.28(\mathrm{~m}$, 2H, 2c-H, 3d-H), 4.14 (dd, $1 \mathrm{H}, J=5.7,9.7 \mathrm{~Hz}, 5 \mathrm{c}-\mathrm{H}$ ), 4.08 (dd, 1H, $J=9.5,9.9 \mathrm{~Hz}, 6 \mathrm{c}-\mathrm{H}), 3.99$ (br d, $1 \mathrm{H}, J=8 \mathrm{~Hz}, 4 \mathrm{~d}-\mathrm{H}), 3.64$ (dd, $1 \mathrm{H}$, $J=2.3,10.6 \mathrm{~Hz}, 3 \mathrm{c}-\mathrm{H}), 3.61$ (dd, $1 \mathrm{H}, J=5.5,9.9 \mathrm{~Hz}, 6 \mathrm{c}-\mathrm{H}), 3.14$ (dd, $1 \mathrm{H}, J=3.8,10.5 \mathrm{~Hz}, 2 \mathrm{~d}-\mathrm{H}), 3.08(\mathrm{~s}, 1 \mathrm{H}, \mathrm{OH}), 1.07(\mathrm{~s}, 9 \mathrm{H}, t-\mathrm{Bu}), 0.90$ (d, $3 \mathrm{H}, J=6.4 \mathrm{~Hz}, 6 \mathrm{~d}-\mathrm{H}) ;{ }^{13} \mathrm{C}$ NMR (150.9 MHz, $\left.\mathrm{CDCl}_{3}\right) \delta=158.5(\mathrm{Z})$, 137.4-127.6 (30C, Ar), 98.6 (C-1d), 87.6 (C-1c), 77.2 (C-3c), 72.7 (Bn), 72.2 (C-4c), 70.9 (C-5c), 69.2 (C-3d), $67.7(\mathrm{Z}), 65.0$ (C-5d), 61.1 (C-2d), 60.9 (C-2c), 60.6 (C-6c), $56.2(\mathrm{C}-4 \mathrm{~d}), 27.1\left(\mathrm{C}\left(\mathrm{CH}_{3}\right)_{3}\right), 19.4$ $\left(\mathrm{C}\left(\mathrm{CH}_{3}\right)_{3}\right), 16.6$ (C-6d). HRMS $[\mathrm{M}+\mathrm{Na}]^{+} \mathrm{m} / \mathrm{z} 952.3500$, found 952.3522.

The same procedure was employed for the transformation of

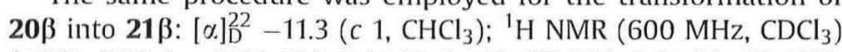
$\delta 7.70-7.30(\mathrm{~m}, 25 \mathrm{H}, \mathrm{Ph}), 5.16\left(2 \mathrm{~d}, 2 \mathrm{H}, \mathrm{CH}_{2}(\mathrm{Z})\right), 5.06(\mathrm{~d}, 1 \mathrm{H}, \mathrm{NH})$, $5.00\left(\mathrm{~d}, 1 \mathrm{H}, \mathrm{J}_{1,2}=3.6 \mathrm{~Hz}, 1 \mathrm{~d}-\mathrm{H}\right), 4.74\left(2 \mathrm{~d}, 2 \mathrm{H}, \mathrm{CH}_{2} \mathrm{Ph}\right), 4.43(\mathrm{~m}, 1 \mathrm{H}, 5 \mathrm{~d}-$ $\mathrm{H}), 4.25\left(\mathrm{~d}, 1 \mathrm{H}, J_{1,2}=9.6 \mathrm{~Hz}, 1 \mathrm{c}-\mathrm{H}\right), 4.17(\mathrm{~m}, 2 \mathrm{H}, 4 \mathrm{c}-\mathrm{H}, 6 \mathrm{~d}-\mathrm{H}), 4.05(\mathrm{~m}$, $1 \mathrm{H}, 3 \mathrm{~d}-\mathrm{H}), 3.89(\mathrm{~m}, 2 \mathrm{H}, 4 \mathrm{~d}-\mathrm{H}, 6 \mathrm{c}-\mathrm{H}), 3.65\left(\mathrm{t}, 1 \mathrm{H},{ }^{3} \mathrm{~J}=10.2 \mathrm{~Hz}, 2 \mathrm{c}-\mathrm{H}\right)$, $3.30\left(\mathrm{dd}, 1 \mathrm{H}, J_{2,1}=3.6 \mathrm{~Hz}, J_{2,3}=10.2 \mathrm{~Hz}, 2 \mathrm{~d}-\mathrm{H}\right), 2.70(\mathrm{~m}, 1 \mathrm{H}, 5 \mathrm{c}-\mathrm{H})$, $3.23\left(\mathrm{dd}, 1 \mathrm{H}, J_{3,4}=2.4 \mathrm{~Hz}, J_{3,2}=10.2 \mathrm{~Hz}, 3 \mathrm{c}-\mathrm{H}\right), 3.12(\mathrm{~d}, 1 \mathrm{H}, \mathrm{OH}), 1.09$ $\left(\mathrm{m}, 9 \mathrm{H}, \mathrm{C}\left(\mathrm{CH}_{3}\right)_{3}\right), 0.92(\mathrm{~d}, 3 \mathrm{H}, J=6.4 \mathrm{~Hz}, 6 \mathrm{~d}-\mathrm{H}) .{ }^{13} \mathrm{C}$ NMR $(150.9 \mathrm{MHz}$, $\left.\mathrm{CDCl}_{3}\right) \delta 159.5(\mathrm{C}=\mathrm{OX}), 138.26-128.7(\mathrm{Ph}), 98.0(\mathrm{C}-1 \mathrm{~d}), 85.6(\mathrm{C}-1 \mathrm{c})$, 79.8 (C-3c), $78.2(\mathrm{C}-5 \mathrm{C}), 72.3\left(\mathrm{CH}_{2} \mathrm{Ph}\right), 71.6$ (C-4c), 70.1 (C-3d), 67.6 $\left(\mathrm{CH}_{2}(\mathrm{Z})\right), 64.7$ (C-5d), $61.6(\mathrm{C}-2 \mathrm{~d}), 61.1$ (C-2c), 60.6 (C-6c) 55.9 (C$4 \mathrm{~d}), 27.9(\mathrm{C}-6 \mathrm{~d}), 20.21\left(\mathrm{C}\left(\mathrm{CH}_{3}\right)_{3}\right), 17.5\left(\mathrm{C}\left(\mathrm{CH}_{3}\right)_{3}\right)$. MALDI-MS (positive mode, matrix DHB, THF): $[\mathrm{M}+\mathrm{Na}]^{+} \mathrm{m} / \mathrm{z}$ 952.4, found 952.3 . $\mathrm{C}_{48} \mathrm{H}_{55} \mathrm{~N}_{7} \mathrm{O}_{8} \mathrm{SSi}$ (930.15): C 63.27, H 5.96, N 10.54, found C 63.05, H $5.78, \mathrm{~N} 10.38$.

4.1.13. Phenyl (2,3,4,6-tetra-O-benzyl- $\beta$-D-glucopyranosyl)-(1-3)-(2azido-4-benzyloxycarbonylamino-2,4,6-trideoxy- $\alpha-D$ -
galactopyranosyl)-(1-4)-2-azido-3-0-benzyl-6-O-tert-butyl-diphe-

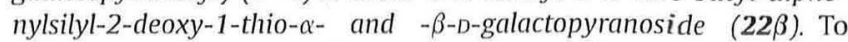
a solution of acceptor $21 \beta(0.850 \mathrm{~g}, 0.91 \mathrm{mmol})$ cooled to $-40{ }^{\circ} \mathrm{C}$ and donor 10 (1.25 g, 2.00 equiv) in acetonitrile $(80 \mathrm{~mL})$ TMSOTf ( $16.5 \mu \mathrm{L}, 0.1 \mathrm{mmol}$ ) was added dropwise. The reaction mixture was stirred for $1 \mathrm{~h}$ at $-40{ }^{\circ} \mathrm{C}$ and $\mathrm{Et}_{3} \mathrm{~N}$ was added. The solvent was evaporated in vacuo. Flash chromatography (petroleum ether/ EtOAc $5: 1)$ yielded $22 \beta(1.07 \mathrm{~g}, 81 \%)$ as a pale yellow syrup. TLC (petroleum ether/EtOAc 5:1) $R_{f}=0.24$. $[\alpha]_{\mathrm{D}}^{22}+15.8\left(c \quad 1, \mathrm{CHCl}_{3}\right) ;{ }^{1} \mathrm{H}$ NMR $\left(600 \mathrm{MHz}, \mathrm{CDCl}_{3}\right) \delta 7.70-7.10(\mathrm{~m}, 45 \mathrm{H}, \mathrm{Ph}), 5.12(\mathrm{~m}, 2 \mathrm{H}, 1 \mathrm{~d}-\mathrm{H}$, $\left.\mathrm{CH}_{2}(\mathrm{Z})\right), 5.03\left(\mathrm{~m}, 2 \mathrm{H}, \mathrm{CH}_{2} \mathrm{Ph}, \mathrm{CH}_{2}(\mathrm{Z})\right), 4.92\left(\mathrm{~m}, 2 \mathrm{H}, \mathrm{CH}_{2} \mathrm{Ph}, \mathrm{NH}\right), 4.82$ $\left(\mathrm{m}, 3 \mathrm{H}, \mathrm{CH}_{2} \mathrm{Ph}\right), 4.72\left(\mathrm{~m}, 4 \mathrm{H}, 1 \mathrm{e}-\mathrm{H}, \mathrm{CH}_{2} \mathrm{Ph}\right), 4.60\left(\mathrm{~m}, 2 \mathrm{H}, \mathrm{CH}_{2} \mathrm{Ph}\right), 4.38$ $(\mathrm{m}, 1 \mathrm{H}, 5 \mathrm{~d}-\mathrm{H}), 4.25(\mathrm{~m}, 3 \mathrm{H}, 1 \mathrm{c}-\mathrm{H}, 4 \mathrm{c}-\mathrm{H}, 4 \mathrm{e}-\mathrm{H}), 4.10(\mathrm{~m}, 2 \mathrm{H}, 6 \mathrm{c}-\mathrm{H}, 3 \mathrm{cl}-$ $\mathrm{H}), 3.89(\mathrm{~m}, 1 \mathrm{H}, 6 \mathrm{e}-\mathrm{H}), 3.80(\mathrm{~m}, 2 \mathrm{H}), 3.70(\mathrm{~m}, 3 \mathrm{H}, 2 \mathrm{c}-\mathrm{H}, 3 \mathrm{~d}-\mathrm{H}, 4 \mathrm{~d}-\mathrm{H})$, $3.55(\mathrm{~m}, 2 \mathrm{H}, 2 \mathrm{e}-\mathrm{H}, 5 \mathrm{e}-\mathrm{H}), 3.20(\mathrm{~m}, 3 \mathrm{H}, 3 \mathrm{c}-\mathrm{H}, 5 \mathrm{c}-\mathrm{H}, 2 \mathrm{~d}-\mathrm{H}), 1.1(\mathrm{~m}, 9 \mathrm{H}$, $\left.\mathrm{C}\left(\mathrm{CH}_{3}\right)_{3}\right), 1.00(\mathrm{~d}, 3 \mathrm{H}, 6 \mathrm{~d}-\mathrm{H}) .{ }^{13} \mathrm{C}$ NMR $\left(150.9 \mathrm{MHz}, \mathrm{CDCl}_{3}\right) \delta 157.00$ $\left(\mathrm{CH}_{2} \mathrm{CO}\right), 139.66-128.44(\mathrm{Ph}), 103.7(\mathrm{C}-1 \mathrm{e}), 98.5(\mathrm{C}-1 \mathrm{~d}), 86.8(\mathrm{C}-1 \mathrm{c})$, 84.7 (C-3e), 82.3 (C-5e), 79.6 (C-5c), 78.3 (C-3c), 77.8 (C-4d), 75.0 (2C, $\left.\mathrm{CH}_{2} \mathrm{Ph}, \mathrm{C}-2 \mathrm{e}\right), 74.7\left(2 \mathrm{C}, \mathrm{CH}_{2} \mathrm{Ph}\right), 74.3(\mathrm{C}-3 \mathrm{~d}), 73.0\left(\mathrm{CH}_{2} \mathrm{Ph}\right), 72.5$ $\left(\mathrm{CH}_{2} \mathrm{Ph}\right), 71.4(\mathrm{C}-4 \mathrm{c}), 68.7(\mathrm{C}-6 \mathrm{e}), 66.5\left(\mathrm{CH}_{2}(\mathrm{Z})\right), 65.7(\mathrm{C}-5 \mathrm{~d}), 61.6(\mathrm{C}-$ 2c), 60.9 (C-6c), 60.6 (C-2d), 55.4 (C-4d), 27.95 (2C, C-6d, $\left.\mathrm{CH}_{3} \mathrm{CO}\right)$, $20.20\left(\mathrm{C}\left(\mathrm{CH}_{3}\right)_{3}\right), 17.63\left(\mathrm{C}\left(\mathrm{CH}_{3}\right)_{3}\right)$. MALDI-MS (positive mode, matrix DHB, THF): $[\mathrm{M}+\mathrm{Na}]^{+} \mathrm{m} / z$ 1474.6, found $m / z$ 1474.6. $\mathrm{C}_{83} \mathrm{H}_{89} \mathrm{~N}_{7} \mathrm{O}_{13} \mathrm{SS}$ (1452.78): C 68.62, H 6.17, N 6.75, found C 68.49, H 5.99, N 7.01.

The same procedure was employed for the transformation of $\mathbf{1 0}$ and $21 \alpha$ into 22 $\alpha$ : TLC (petroleum ether/EtOAc, 5:1) $R_{f}=0.45$. $\nu_{\max }($ ATR $) 2108,1729 \mathrm{~cm}^{-1} ;{ }^{1} \mathrm{H}$ NMR $\left(600 \mathrm{MHz}, \mathrm{CDCl}_{3}\right) \delta 7.70-7.10$ $(\mathrm{m}, 45 \mathrm{H}, \mathrm{Ph}), 5.50(\mathrm{br} \mathrm{d}, 1 \mathrm{H}, J=5.2 \mathrm{~Hz}, 1 \mathrm{c}-\mathrm{H}), 5.25(\mathrm{~d}, 1 \mathrm{H}, J=4.0 \mathrm{~Hz}$, $1 \mathrm{~d}-\mathrm{H}), 5.13$ (br d, $1 \mathrm{H}, J=12.3 \mathrm{~Hz}, \mathrm{Z}), 5.01(\mathrm{br} \mathrm{d}, 1 \mathrm{H}, J=12.3 \mathrm{~Hz}, \mathrm{Z}$ ), 4.96-4.45 (m, 15H, Bn, 1e-H, 5d-H, NH), 4.42 (br s, 1H, 4c-H), 4.32 $(\mathrm{m}, 2 \mathrm{H}, 3 \mathrm{~d}-\mathrm{H}, 4 \mathrm{~d}-\mathrm{H}), 4.28(\mathrm{dd}, 1 \mathrm{H}, J=5.2,10.6 \mathrm{~Hz}, 2 \mathrm{c}-\mathrm{H}), 4.14(\mathrm{~m}, 1 \mathrm{H}$ $5 \mathrm{c}-\mathrm{H}), 4.07(\mathrm{~m}, 1 \mathrm{H}, 6 \mathrm{c}-\mathrm{H}), 3.83-3.47\left(\mathrm{~m}, 8 \mathrm{H}, 3 \mathrm{c}-\mathrm{H}, 6^{\prime} \mathrm{c}-\mathrm{H}, 2 \mathrm{e}-\mathrm{H}, 3 \mathrm{e}-\right.$ $\left.\mathrm{H}, 4 \mathrm{e}-\mathrm{H}, 5 \mathrm{e}-\mathrm{H}, 6 \mathrm{e}-\mathrm{H}, \mathrm{G}^{\prime} \mathrm{e}-\mathrm{H}\right), 3.11$ (br d, $\left.1 \mathrm{H}, J=9.0 \mathrm{~Hz}, 2 \mathrm{~d}-\mathrm{H}\right), 1.09(\mathrm{~s}$ $9 \mathrm{H}), 0.99(\mathrm{~d}, 3 \mathrm{H}, J=6.4 \mathrm{~Hz}, 6 \mathrm{~d}-\mathrm{H}) .{ }^{13} \mathrm{C}$ NMR $\left(150.9 \mathrm{MHz}^{-\mathrm{CDCl}_{3}}\right)$ o $156.5(\mathrm{C}=\mathrm{O}, \mathrm{Z}), 138.8-127.3(\mathrm{Ph}), 103.5(\mathrm{C}-1 \mathrm{e}), 98.7(\mathrm{C}-1 \mathrm{~d}), 87.6$ (C-1c), 86.0-67.0 (5x Bn, Z, C-3e, C-4e, C-6e), 82.6 (C-2c), 71.9 (C4c), 76.7 (C-3c), 73.2 (C-3d), 70.7 (C-5c), 65.9 (C-5d), $60.6(C-6 c)$,

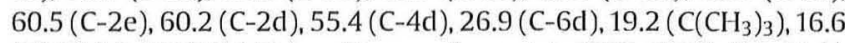
$\left(\mathrm{C}\left(\mathrm{CH}_{3}\right)_{3}\right)$. MALDI-MS (positive mode, matrix DHB, THF): $[\mathrm{M}+\mathrm{Na}]^{\prime}$ $\mathrm{m} / \mathrm{z}$ 1474.6, found 1474.9 .

4.1.14. (2,3,4,6-Tetra-O-benzyl- $\beta$-D-glucopyranosyl)-(1-3)-(2-azido4-benzyloxycarbonylamino-2,4,6-trideoxy- $\alpha$-D-galactopyranosyl)(1-4)-2-azido-3-0-benzyl-6-0-tert-butyl-diphenylsilyl-2-deoxy- $\alpha, \beta$ D-galactopyranose (23). To a solution of $22 \alpha$ or $22 \beta(1.07 \mathrm{~g}$, $0.72 \mathrm{mmol})$ cooled to $-15{ }^{\circ} \mathrm{C}$ in acetone $(35 \mathrm{~mL})$ NBS $(0.180 \mathrm{~g}$, 1.4 equiv) was added and the reaction mixture stirred for $3 \mathrm{~h}$ at that temperature. The reaction was quenched with saturated $\mathrm{NaHCO}_{3}$ solution and extracted three times with $\mathrm{CH}_{2} \mathrm{Cl}_{2}$. The organic phase was dried over sodium sulfate and the solvent removed in vacuo. Flash chromatography (petroleum ether/EtOAc 3:1) yielded 23 $(0.985 \mathrm{~g}, 91 \%)$ as a colourless wax. TLC (petroleum ether/EtOAc 3:1) $R_{f}=0.28 .[\alpha]_{\mathrm{D}}^{22}+5.5\left(c \quad 1, \mathrm{CHCl}_{3}\right) ; v_{\max }(\mathrm{ATR}) 3356(\mathrm{br}), 2109$, $1720 \mathrm{~cm}^{-1} ;{ }^{1} \mathrm{H}$ NMR (250 MHz, CDCl $) \delta 7.7-7.1(\mathrm{~m}, 40 \mathrm{H}, \mathrm{Ph}), 5.12$ $\left(\mathrm{m}, 2 \mathrm{H}, \mathrm{CH}_{2}(\mathrm{Z})\right), 5.03\left(\mathrm{~m}, 2 \mathrm{H}, \mathrm{CH}_{2} \mathrm{Ph}, \mathrm{CH}_{2}(\mathrm{Z})\right), 4.92\left(\mathrm{~m}, 2 \mathrm{H}, \mathrm{CH}_{2} \mathrm{Ph}\right.$, $\mathrm{NH}), 4.82\left(\mathrm{~m}, 3 \mathrm{H}, \mathrm{CH}_{2} \mathrm{Ph}\right), 4.72\left(\mathrm{~m}, 4 \mathrm{H}, 1 \mathrm{e}-\mathrm{H}, \mathrm{CH}_{2} \mathrm{Ph}\right), 4.64(\mathrm{~m}, 2 \mathrm{H}$, $\left.\mathrm{CH}_{2} \mathrm{Ph}\right), 4.38(\mathrm{~m}, 1 \mathrm{H}, 5 \mathrm{~d}-\mathrm{H}), 4.25(\mathrm{~m}, 3 \mathrm{H}, 1 \mathrm{c}-\mathrm{H}, 4 \mathrm{c}-\mathrm{H}, 4 \mathrm{~d}-\mathrm{H}), 4.12(\mathrm{~m}$, $2 \mathrm{H}, 6 \mathrm{c}-\mathrm{H}, 3 \mathrm{~d}-\mathrm{H}), 3.89\left(\mathrm{~m}, 1 \mathrm{H}, 6 \mathrm{f}^{\prime}-\mathrm{H}\right), 3.81(\mathrm{~m}, 2 \mathrm{H}, 6 \mathrm{e}-\mathrm{H}), 3.73(\mathrm{~m}, 3 \mathrm{H}$, $2 \mathrm{c}-\mathrm{H}, 3 \mathrm{e}-\mathrm{H}, 4 \mathrm{e}-\mathrm{H}), 3.55(\mathrm{~m}, 2 \mathrm{H}, 2 \mathrm{e}-\mathrm{H}, 5 \mathrm{e}-\mathrm{H}), 3.22$ (m, 3H, 3c-H, 5c-H, 2d-H), $1.15\left(\mathrm{~m}, 9 \mathrm{H}, \mathrm{C}\left(\mathrm{CH}_{3}\right)_{3}\right), 1.0(\mathrm{~d}, 3 \mathrm{H}, 6 \mathrm{~d}-\mathrm{H})$. MALDI-MS (positive mode, matrix DHB, THF): $[\mathrm{M}+\mathrm{Na}]^{+} \mathrm{m} / \mathrm{z} 1382.6$, found $\mathrm{m} / \mathrm{z}$ 1382.6. $\mathrm{C}_{77} \mathrm{H}_{85} \mathrm{~N}_{7} \mathrm{O}_{14} \mathrm{SSi}$ (1360.62): C 67.97, H 6.30, N 7.21, found C 68.16, H $6.42, \mathrm{~N} 7.01$.

4.1.15. $O-[(2,3,4,6$-Tetra-O-benzyl- $\beta$-D-glucopyranosyl)-(1-3)-(2azido-4-benzyloxycarbonylamino-2, 4, 6-trideoxy- $\alpha-D-$ 
galactopyranosyl)-(1-4)-2-azido-3-0-benzyl-6-0-tert-butyl-diphenylsilyl-2-deoxy- $\alpha$-D-galactopyranosyl] trichloroacetimidate (5). To a solution of $23(0.97 \mathrm{~g}, 0.79 \mathrm{mmol})$ in $\mathrm{CH}_{2} \mathrm{Cl}_{2}(10 \mathrm{~mL}) \mathrm{CCl}_{3} \mathrm{CN}(1.57 \mathrm{~mL}$, 20 equiv) and $\mathrm{DBU}(11.7 \mu \mathrm{L}, 0.1$ equiv) were added, the reaction mixture stirred for $1.5 \mathrm{~h}$ and the solvent evaporated in vacuo. Flash chromatography (petroleum ether/EtOAc 3:1) yielded 5 ( $0.99 \mathrm{~g}, 91 \%)$ as a pale yellow syrup. TLC (petroleum ether/EtOAc $5: 1$ ) $R_{f}=0.31,{ }^{1} \mathrm{H}$ NMR ( $\left.600 \mathrm{MHz}, \mathrm{CDCl}_{3}\right) \delta 8.48(\mathrm{~s}, 1 \mathrm{H}, \mathrm{NH}$-imidate), 7.7-7.1 (m, 40H, $\mathrm{Ph}), 6.73(\mathrm{~s}, 1 \mathrm{H}, 1 \mathrm{c}-\mathrm{H}), 5.12\left(\mathrm{~m}, 2 \mathrm{H}, 1 \mathrm{~d}-\mathrm{H}, \mathrm{CH}_{2}(\mathrm{Z})\right), 5.03\left(\mathrm{~m}, 2 \mathrm{H}, \mathrm{CH}_{2} \mathrm{Ph}\right.$, $\left.\mathrm{CH}_{2}(\mathrm{Z})\right), 4.92\left(\mathrm{~m}, 2 \mathrm{H}, \mathrm{CH}_{2} \mathrm{Ph}, \mathrm{NH}\right), 4.82\left(\mathrm{~m}, 3 \mathrm{H}, \mathrm{CH}_{2} \mathrm{Ph}\right), 4.72(\mathrm{~m}, 4 \mathrm{H}, 1 \mathrm{e}-$ $\left.\mathrm{H}, \mathrm{CH}_{2} \mathrm{Ph}\right), 4.6\left(\mathrm{~m}, 2 \mathrm{H}, \mathrm{CH}_{2} \mathrm{Ph}\right), 4.38(\mathrm{~m}, 1 \mathrm{H}, 5 \mathrm{~d}-\mathrm{H}), 4.25(\mathrm{~m}, 2 \mathrm{H}, 4 \mathrm{c}-\mathrm{H}$, $4 \mathrm{~d}-\mathrm{H}), 4.10(\mathrm{~m}, 2 \mathrm{H}, 6 \mathrm{c}-\mathrm{H}, 3 \mathrm{cl}-\mathrm{H}), 3.89\left(\mathrm{~m}, 1 \mathrm{H}, 6 \mathrm{a}^{\prime}-\mathrm{H}\right), 3.80(\mathrm{~m}, 2 \mathrm{H}, 6 \mathrm{e}-$ $\mathrm{H}), 3.70(\mathrm{~m}, 3 \mathrm{H}, 2 \mathrm{c}-\mathrm{H}, 3 \mathrm{e}-\mathrm{H}, 4 \mathrm{e}-\mathrm{H}), 3.55(\mathrm{~m}, 2 \mathrm{H}, 2 \mathrm{e}-\mathrm{H}, 5 \mathrm{e}-\mathrm{H}), 3.25(\mathrm{~m}$, $3 \mathrm{H}, 3 \mathrm{c}-\mathrm{H}, 5 \mathrm{c}-\mathrm{H}, 2 \mathrm{~d}-\mathrm{H}), 1.10\left(\mathrm{~m}, 9 \mathrm{H}, \mathrm{C}\left(\mathrm{CH}_{3}\right)_{3}\right), 1.00(\mathrm{~d}, 3 \mathrm{H}, 6 \mathrm{~d}-\mathrm{H})$. MALDI-MS (positive mode, matrix DHB, THF): $[\mathrm{M}+\mathrm{Na}]^{+} \mathrm{m} / \mathrm{z}$ 1525.5, found 1474.6 (OH free). $\mathrm{C}_{79} \mathrm{H}_{85} \mathrm{Cl}_{13} \mathrm{~N}_{8} \mathrm{O}_{14} \mathrm{Si}$ (1505.01): C 63.05, $\mathrm{H}$ 5.69, N 7.45, found C 63.21, H 5.88, N 7.55.

4.1.16. 5-0-Allyl-2,3,4-tri-0-benzyl-1-0-(3-0-acetyl-2-azido-4-0benzyl-6-O-tert-butyl-diphenylsilyl-2-deoxy- $\beta$-D-galactopyranosyl)D-ribitol (24). Donor 7 ( $0.78 \mathrm{~g}, 1.2$ equiv) and acceptor 6 ( $0.420 \mathrm{~g}$, $0.91 \mathrm{mmol}$ ) were dried $1 \mathrm{~h}$ under vacuum and dissolved in acetonitrile $(15 \mathrm{~mL})$, the solution was cooled to $-40{ }^{\circ} \mathrm{C}$ and TMSOTf (24.6 $\mu \mathrm{L}, 0.15$ equiv) was added dropwise. The reaction mixture was stirred at $-40^{\circ} \mathrm{C}$ for $2 \mathrm{~h}$ and $\mathrm{Et}_{3} \mathrm{~N}$ was added to quench the reaction. The solvent was evaporated in vacuo. Flash chromatography (petroleun ether/EtOAc 3:1) yielded $\mathbf{2 4}(0.748 \mathrm{~g}, 81 \%)$ as a pale yellow syrup. TLC (petroleum ether/EtOAc 8:1) $R_{f}=0.2$. $[\alpha]_{\mathrm{D}}^{22}+8.1$ ( $c 1$, $\left.\mathrm{CHCl}_{3}\right) ;{ }^{1} \mathrm{H}$ NMR $\left(250 \mathrm{MHz}, \mathrm{CDCl}_{3}\right) \delta 7.60-7.05(\mathrm{~m}, 30 \mathrm{H}, \mathrm{Ph}), 5.80$ (m, 1H, CH-All), 5.15 (m, 2H, CH - All), $4.80-4.50(\mathrm{~m}, 9 \mathrm{H}, 4 \times$ $\left.\mathrm{CH}_{2} \mathrm{Ph}, 3 \mathrm{~b}-\mathrm{H}\right), 4.25\left(\mathrm{~d}, 1 \mathrm{H}, J_{1,2}=8.1 \mathrm{~Hz}, 1 \mathrm{~b}-\mathrm{H}\right), 4.10-3.45(\mathrm{~m}, 14 \mathrm{H}, 1 \mathrm{a}-$ H, 2a-H, 3a-H, 4a-H, 5a-H, 2b-H, 4b-H, 5b-H, 6b-H, CH $2-$ All), 2.05 (s, 3H, $\left.\mathrm{CH}_{3} \mathrm{CO}\right), 1.05\left(\mathrm{~s}, 9 \mathrm{H}, \mathrm{C}\left(\mathrm{CH}_{3}\right)\right) .{ }^{13} \mathrm{C}$ NMR $\left(101 \mathrm{MHz}, \mathrm{CDCl}_{3}\right)$ $\delta 138.8,138.7,138.6,138.6,135.6,135.0,133.2,133.2,129.9,129.8$, $128.2,128.2,128.2,128.1,127.9,127.9,127.8,127.8,127.8,127.5,127.4$, 116.6, 102.1, 81.6, 78.6, 78.5, 78.3, 74.9, 74.7, 73.8, 72.4, 72.3, 72.2, $72.0,70.3,68.7,66.0,63.2,62.2,26.9,19.2,15.5$. MALDI-MS (positive mode, matrix DHB, THF): $[\mathrm{M}+\mathrm{Na}]^{+} \mathrm{m} / \mathrm{z}$ 1042.5, found 1042.6. $[\mathrm{M}+\mathrm{K}]^{+} \mathrm{m} / \mathrm{z}$ 1058.5, found 1058.5. $\mathrm{C}_{60} \mathrm{H}_{69} \mathrm{~N}_{3} \mathrm{O}_{10} \mathrm{Si}$ (1020.29): C 70.63, H 6.82, N 4.12, found C 70.88, H 7.03, N 4.29.

4.1.17. 5-O-Allyl-2,3,4-tri-O-benzyl-1-O-(2-azido-4-O-benzyl-6-Otert-butyl-diphenylsilyl-2-deoxy- $\beta$-D-galactopyranosyl)-D-ribitol (4). Compound 24 ( $0.72 \mathrm{~g}, 0.71 \mathrm{mmol}$ ) was dissolved in $\mathrm{MeOH}$ and a freshly prepared NaOMe solution $(0.2 \mathrm{M})$ was added dropwise until $\mathrm{pH}=9$. The reaction mixture was stirred for $2 \mathrm{~h}$ and amberlite IR-120 acid resin was added until neutralization. The mixture was filtrated and the solvent removed in vacuo, which yielded $23(0.69 \mathrm{~g}$, $100 \%$ ) as a pale yellow oil. TLC (petroleum ether/EtOAc 5:1) $R_{f}=0.32$. $[\alpha]_{\mathrm{D}}^{22}+12.1\left(\mathrm{c} 1, \mathrm{CHCl}_{3}\right) ; \nu_{\max }($ ATR $) 2112(\mathrm{~s}) \mathrm{cm}^{-1} ;{ }^{1} \mathrm{H} \mathrm{NMR}(250 \mathrm{MHz}$, $\left.\mathrm{CDCl}_{3}\right) \delta 7.6-7.05(\mathrm{~m}, 30 \mathrm{H}, \mathrm{Ph}), 5.8(\mathrm{~m}, 1 \mathrm{H}, \mathrm{CH}-\mathrm{All}), 5.15(\mathrm{~m}, 2 \mathrm{H}$, $\left.\mathrm{CH}_{2}-\mathrm{All}\right), 4.8-4.5\left(\mathrm{~m}, 8 \mathrm{H}, 4 \times \mathrm{CH}_{2} \mathrm{Ph}\right), 4.25\left(\mathrm{~d}, 1 \mathrm{H}, J_{1,2}=8.1 \mathrm{~Hz}, 1 \mathrm{~b}-\mathrm{H}\right)$, 4.1-3.55 (m, 14H, 1a-H, 2a-H, 3a-H, 4a-H, 5a-H, 2b-H, 4b-H, 5b-H, $6 \mathrm{~b}-\mathrm{H}, \mathrm{CH}_{2}-\mathrm{All}$ ), 3.45 (dd, $1 \mathrm{H}, J_{4,3}=7.8 \mathrm{~Hz}, J_{4,5}=5.9 \mathrm{~Hz}, 3 \mathrm{~b}-\mathrm{H}$ ), 1.05 (s, $\left.9 \mathrm{H}, \mathrm{C}\left(\mathrm{CH}_{3}\right)\right) .{ }^{13} \mathrm{C}$ NMR $\left(101 \mathrm{MHz}, \mathrm{CDCl}_{3}\right) \delta 138.8-127.4$ (Ar; CH-All), 116.7 (All), 102.3 (C-1b), 78.7, 78.5, 78.5 (C-2a, C-3a, C-4a), 77.4, 75.5 (Bn), 75.4, 74.8 (C-4b, C-5b), $73.8(\mathrm{Bn}), 72.4(\mathrm{C}-3 \mathrm{~b}), 72.2\left(\mathrm{CH}_{2}-\mathrm{All}\right.$,

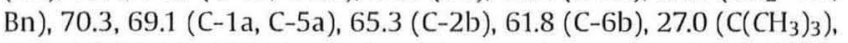

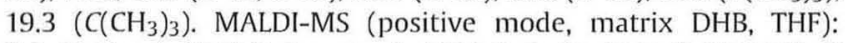
$[\mathrm{M}+\mathrm{Na}]^{+} \mathrm{m} / \mathrm{z} 1000.5$, found $\mathrm{m} / \mathrm{z} 1000.6 . \mathrm{C}_{60} \mathrm{H}_{67} \mathrm{~N}_{3} \mathrm{O} 9 \mathrm{Si}(978.25): \mathrm{C}$ 71.21, H 6.90, N 4.30, found C 70.98, H 7.03, N 4.41.

4.1.18. 5-O-Allyl-2,3,4-tri-O-benzyl-1-O-[(2,3,4,6-tetra-O-benzyl- $\beta$ D-glucopyranosyl)-(1-3)-(2-azido-4-benzyloxycarbonylamino-2,4,6trideoxy- $\alpha$-D-galactopyranosyl)-(1-4)-(2-azido-3-0-benzyl-6-0tert-butyl-diphenylsilyl-2-deoxy- $\alpha$-D-galactopyranosyl)-(1-3)-(2-
azido-4-O-benzyl-6-O-tert-butyl-diphenylsilyl-2-deoxy- $\beta$-D-galactopyranosyl)-D-ribitol (25). To a solution of acceptor $4(0.315 \mathrm{~g}$, $0.5 \mathrm{mmol}$ ) and donor 5 ( $0.485 \mathrm{~g}, 1$ equiv) in $\mathrm{CH}_{2} \mathrm{Cl}_{2}, 4 \mathrm{~A}$ molecular sieves were added. After 60 min the reaction mixture was cooled to $0{ }^{\circ} \mathrm{C}$ and TMSOTf (ca. $10 \mathrm{mg}$ in $0.5 \mathrm{~mL} \mathrm{CH}_{2} \mathrm{Cl}_{2}$ ) was added dropwise. The reaction mixture was stirred for $1.5 \mathrm{~h}$ at $0{ }^{\circ} \mathrm{C}$ and allowed to reach $10{ }^{\circ} \mathrm{C}$ before $\mathrm{Et}_{3} \mathrm{~N}$ was added to neutralize. The solvent was removed in vacuo. Flash chromatography (toluene/EtOAc 30:1) yielded $25(0.664 \mathrm{~g}, 89 \%)$ as a colourless amorphous solid. TLC (toluene/EtOAc 20:1) $R_{f}=0.42 .[\alpha]_{D}^{22}-19.2\left(c 1, \mathrm{CHCl}_{3}\right) ; \nu_{\max }$ (ATR) 2109, $1725 \mathrm{~cm}^{-1}$; ${ }^{1} \mathrm{H}$ NMR (600 MHz, $\left.\mathrm{CDCl}_{3}\right) \delta 7.7-7.1(\mathrm{~m}, 70 \mathrm{H}, \mathrm{Ph})$, 5.75 ( $\mathrm{m}, 1 \mathrm{H}, \mathrm{CH}-\mathrm{All}), 5.3-5.1\left(\mathrm{~m}, 4 \mathrm{H}, \mathrm{CH}_{2}-\mathrm{All}, 1 \mathrm{~d}-\mathrm{H}, 1 \mathrm{c}-\mathrm{H}\right), 5.1-4.6$ $\left(\mathrm{m}, 21 \mathrm{H}, 9 \times \mathrm{CH}_{2} \mathrm{Ph}, \mathrm{CH}_{2}(\mathrm{Z}), 1 \mathrm{e}-\mathrm{H}\right), 4.5(\mathrm{~m}, 1 \mathrm{H}, 5 \mathrm{cl}-\mathrm{H}), 4.45(\mathrm{~m}, 1 \mathrm{H}, 4 \mathrm{c}-$ $\mathrm{H}), 4.3(\mathrm{~m}, 2 \mathrm{H}, 4 \mathrm{~d}-\mathrm{H}, 3 \mathrm{~d}-\mathrm{H}), 4.17(\mathrm{~m}, 1 \mathrm{H}, 1 \mathrm{a}-\mathrm{H}), 4.1\left(\mathrm{~d}, 1 \mathrm{H}, J_{1,2}=7.6 \mathrm{~Hz}\right.$, 1b-H), 4.05 (m, 4H, 4b-H, 1a-H, 4e-H), 4.0-3.6 (m, 18H, 3e-H, 6e-H, $2 \mathrm{a}-\mathrm{H}, 3 \mathrm{a}-\mathrm{H}, 4 \mathrm{a}-\mathrm{H}, 5 \mathrm{a}-\mathrm{H}, \mathrm{CH}_{2}-\mathrm{All}, 6 \mathrm{~b}-\mathrm{H}, 6 \mathrm{c}-\mathrm{H}, 2 \mathrm{~b}-\mathrm{H}, 2 \mathrm{c}-\mathrm{H}, 5 \mathrm{c}-\mathrm{H}, 5 \mathrm{e}-$ H), $3.5(\mathrm{~m}, 3 \mathrm{H}, 2 \mathrm{e}-\mathrm{H}, 3 \mathrm{~b}-\mathrm{H}, 3 \mathrm{c}-\mathrm{H}), 3.3(\mathrm{~m}, 1 \mathrm{H}, 5 \mathrm{~b}-\mathrm{H}), 3.07(\mathrm{~m}, 1 \mathrm{H}, 2 \mathrm{~d}-$ $\mathrm{H}), 1.05\left(\mathrm{~m}, 18 \mathrm{H}, 2 \times \mathrm{C}\left(\mathrm{CH}_{3}\right)_{3}\right), 0.94(\mathrm{~d}, 3 \mathrm{H}, 6 \mathrm{~g}) .{ }^{13} \mathrm{C} \mathrm{NMR}(150.9 \mathrm{MHz}$, $\left.\mathrm{CDCl}_{3}\right) \delta 158.0(\mathrm{CO}(\mathrm{Z})), 139.5$ ( $\left.\mathrm{CH}-\mathrm{All}\right), 138-128(\mathrm{C}-\mathrm{Ph}), 117.6$ ( $\mathrm{CH}_{2}-\mathrm{All}$ ), 103.4 (C-1e), 102.1 (C-1b), 98.5 (C-1d), 94.5 (C-1c), 84.5 (C-4e), 82.5 (C-2e), 78.6-69.0 (C-1a, C-2a, C-3a, C-4a, C-5a, C-3b, C4b, C-5b, C-3c, C-4c, C-5c, C-3d, C-3e, C-5e, C-6e, CH - All), 66.8 $\left(\mathrm{CH}_{2}(\mathrm{Z})\right), 65.8$ (C-5d), 62.7 (C-2b), 61.7, 60.9 (C-6b, C-6c), 60.0 (C2d), 59.5 (C-2c), $55.4(\mathrm{C}-4 \mathrm{~d}), 27.9\left(\mathrm{C}\left(\mathrm{CH}_{3}\right)_{3}\right), 20.3$ (C-6d). MALDI-MS (positive mode, matrix DHB, THF): $[\mathrm{M}+\mathrm{Na}]^{+} \mathrm{m} / z$ 2342.0, found 2342.0. $\mathrm{C}_{135} \mathrm{H}_{150} \mathrm{~N}_{10} \mathrm{O}_{22} \mathrm{Si}$ (2320.86): C 69.86, H 6.51, N 6.04, found $\mathrm{C}$ 70.09, H 6.73, N 6.21 .

4.1.19. 5-O-Allyl-2,3,4-tri-O-benzyl-1-O-I(2,3,4,6-tetra-O-benzyl- $\beta$ D- gluc op yranosyl) - (1-3) - (2 - a c e tylamino-4 benzyloxycarbonylamino-2,4,6-trideoxy- $\alpha$ - $D$-galactopyranosyl)(1-4)-(2-acetylamino-3-0-benzyl-6-O-tert-butyl-diphenylsilyl-2deoxy- $\alpha$-D-galactopyranosyl)-(1-3)-(2-acetylamino-4-0-benzyl-6O-tert-butyl-diphenylsilyl-2-deoxy- $\beta$-D-galactopyranosyl)]-D-ribitol (26). A solution of $25(0.205 \mathrm{~g}, 0.088 \mathrm{mmol})$ in pyridine/water (3:1, $\mathrm{v} / \mathrm{v}, 4 \mathrm{~mL}$ ) was saturated with $\mathrm{H}_{2} \mathrm{~S}$ and the reaction mixture stirred for 3 days until TLC showed complete conversion of the starting material. The solvent was evaporated in vacuo and the residue coevaporated twice with toluene. The intermediate product was dissolved in pyridine $/ \mathrm{Ac}_{2} \mathrm{O}(1.5: 1, \mathrm{v} / \mathrm{v}, 3 \mathrm{~mL})$ and the reaction mixture stirred overnight. The solvent was evaporated in vacuo and flash chromatography (toluene/EtOAc, 3:1) yielded 26 (0.176 g. $84 \%$ ) as a pale yellow syrup. TLC (toluene/EtOAc 3:1) $R_{f}=0.27$. [a. [ -13.1 (c 1, $\mathrm{CHCl}_{3}$ ); $\nu_{\max }$ (ATR) 3450(br), 3275(br), 1723, $1659 \mathrm{~cm}^{-1}$; ${ }^{1} \mathrm{H}$ NMR $\left(600 \mathrm{MHz}, \mathrm{CDCl}_{3}\right) \delta 7.70-7.10(\mathrm{~m}, 70 \mathrm{H}, \mathrm{Ph}), 6.26(\mathrm{~m}, 1 \mathrm{H}, 2 \mathrm{~d}-$ $\mathrm{NH}), 6.11(\mathrm{~m}, 1 \mathrm{H}, 2 \mathrm{c}-\mathrm{NH}), 5.90(\mathrm{~m}, 1 \mathrm{H}, \mathrm{CH}-\mathrm{All}), 5.30-4.40(\mathrm{~m}, 29 \mathrm{H}$, $\mathrm{CH}_{2}-\mathrm{All}, 1 \mathrm{c}-\mathrm{H}, 2 \mathrm{c}-\mathrm{H}, 1 \mathrm{~d}-\mathrm{H}, 5 \mathrm{~d}-\mathrm{H}, 1 \mathrm{e}-\mathrm{H}, 9 \times \mathrm{CH}_{2} \mathrm{Ph}, \mathrm{CH}_{2}(\mathrm{Z}), 2 \mathrm{~b}-\mathrm{NH}$, 4d-NH), 4.40-3.35 (m, 29H, 1a-H, 2a-H, 3a-H, 4a-H, 5a-H, 1b-H, 2b$\mathrm{H}, 3 \mathrm{~b}-\mathrm{H}, 4 \mathrm{~b}-\mathrm{H}, 6 \mathrm{~b}-\mathrm{H}, 3 \mathrm{c}-\mathrm{H}, 4 \mathrm{c}-\mathrm{H}, 5 \mathrm{c}-\mathrm{H}, 6 \mathrm{c}-\mathrm{H}, 2 \mathrm{~d}-\mathrm{H}, 3 \mathrm{~d}-\mathrm{H}, 4 \mathrm{~d}-\mathrm{H}, 2 \mathrm{e}-$ $\left.\mathrm{H}, 3 \mathrm{e}-\mathrm{H}, 4 \mathrm{e}-\mathrm{H}, 5 \mathrm{e}-\mathrm{H}, 6 \mathrm{e}-\mathrm{H}, \mathrm{CH}_{2}-\mathrm{All}\right), 3.30$ (m, 1H, 5b-H), 1.60-1.40 (3s, $\left.9 \mathrm{H}, 3 \times \mathrm{CH}_{3} \mathrm{C}(\mathrm{O}) \mathrm{N}\right), 1.05\left(\mathrm{~m}, 18 \mathrm{H}, 2 \times \mathrm{C}\left(\mathrm{CH}_{3}\right)_{3}\right), 0.94(\mathrm{~d}, 3 \mathrm{H}, 6 \mathrm{~d}-\mathrm{H})$. ${ }^{13} \mathrm{C}$ NMR $\left(150.9 \mathrm{MHz}, \mathrm{CDCl}_{3}\right) \delta 172-170(\mathrm{CO}-\mathrm{Ac}-\mathrm{N} 2 \mathrm{~b}, \mathrm{CO}-\mathrm{Ac}-\mathrm{N} 2 \mathrm{c}$, CO-Ac-N2d), 158.0 (CO(Z)), 139.5 (CH-All), 138-128 (C-Ph), 117.6 ( $\mathrm{CH}_{2}-\mathrm{All}$ ), 103.4 (C-1e), 102.1 (C-1b), 98.5 (C-1d), 94.5 (C-1c), 84.5 (C-4e), 81.9 (C-2e), 78.6-69.0 (C-1 a, C-2a, C-3a, C-4a, C-5a, C-3b, C4b, C-5b, C-3c, C-4c, C-5c, C-3d, C-3e, C-5e, C-6e), $67.7\left(\mathrm{CH}_{2}-\mathrm{All}\right)$, $66.8\left(\mathrm{CH}_{2}(\mathrm{Z})\right), 66.6(\mathrm{C}-5 \mathrm{~d}), 62.7,62.6$ (C-6b, C-6c), 55.2 (C-4d), 52.9 (C-2b), 50.1 (C-2c, C-2d), $\left.27.9\left(\mathrm{C}^{(} \mathrm{CH}_{3}\right)_{3}\right), 20.3$ (C-6d). MALDI-MS (positive mode, matrix DHB, THF): $[\mathrm{M}+\mathrm{Na}]^{+} \mathrm{m} / z$ 2390.1, found 2390.1. $\mathrm{C}_{141} \mathrm{H}_{162} \mathrm{~N}_{4} \mathrm{O}_{25} \mathrm{Si}$ (2368.98): C 71.49, H 6.89, N 2.37, found $\mathrm{C}$ 71.18, H 6.73, N 2.69 .

4.1.20. 2,3,4-Tri-O-benzyl-1-O-I(2,3,4,6-tetra-O-benzyl- $\beta$-D-glucopyranosyl)-(1-3)-(2-acetylamino-4-benzyloxycarbonylamino-2,4,6trideoxy- $\alpha$-D-galactopyranosyl)-(1-4)-(2-acetylamino-3-0-benzyl-6O-tert-butyl-diphenylsilyl-2-deoxy- $\alpha$-D-galactopyranosyl)-(1-3)-(2- 
acetylamino-4-O-benzyl-6-O-tert-butyl-diphenylsilyl-2-deoxy- $\beta$-Dgalactopyranosyl)]-D-ribitol (27). To a solution of 26 (0.29 g, $0.122 \mathrm{mmol}$ ) in EtOH ( $9 \mathrm{~mL}) \mathrm{DBU}\left(2.8 \mu \mathrm{L}, 0.15\right.$ equiv) and $\left(\mathrm{Ph}_{3} \mathrm{P}\right)_{3} \mathrm{RuCl}_{2}$ $(0.059 \mathrm{~g}, 0.5$ equiv) were added and the reaction mixture was stirred for $20 \mathrm{~min}$ at $90^{\circ} \mathrm{C}$. The solvent was evaporated in vacuo and the residue dissolved in a mixture of acetone $/ \mathrm{HCl} 1 \mathrm{~N}(10 \mathrm{~mL}, 9: 1 \mathrm{v} / \mathrm{v})$. The reaction was stirred for another $15 \mathrm{~min}$ and $\mathrm{Et}_{3} \mathrm{~N}$ was added. The solvent was removed in vacuo. Flash chromatography (toluene/acetone, $5: 1)$ yielded $27(0.22 \mathrm{~g}, 81 \%)$ as a colourless syrup. TLC (toluene/ acetone, 1:1) $R_{f}=0.38$. [a. $]_{\mathrm{D}}^{22}-19.2\left(c 1, \mathrm{CHCl}_{3}\right) . v_{\max }(\mathrm{ATR}) 3294(\mathrm{br})$, $1721,1660 \mathrm{~cm}^{-1} ;{ }^{1} \mathrm{H}$ NMR $\left(600 \mathrm{MHz}, \mathrm{CDCl}_{3}\right) \delta 7.70-7.10(\mathrm{~m}, 70 \mathrm{H}, \mathrm{Ph})$, 6.26 (br s, 1H, 2d-NH), 6.11 (br s, 1H, 2c-NH), 5.20 (br s, 2H, 1c-H, 4a$\mathrm{NH}), 5.10\left(\mathrm{~d}, 1 \mathrm{H}, J_{\mathrm{gem}}=12.6 \mathrm{~Hz}, \mathrm{CH}(\mathrm{Z})\right), 5.05-4.40\left(\mathrm{~m}, 24 \mathrm{H}, 9 \times \mathrm{CH}_{2} \mathrm{Pl}\right.$ 2b-NH, 2c-H, 1e-H, 5cl-H, 1d-H, CH(Z)), 4.40-4.20 (m, 3H, 4c-H, 2a-H, 4a-H), 4.15 (m, 2H, 1b-H, 3d-H), $4.05(\mathrm{~m}, 1 \mathrm{H}, 2 \mathrm{~b}-\mathrm{H}), 4.00-3.35$ (m, $20 \mathrm{H}, 1 \mathrm{a}-\mathrm{H}, 2 \mathrm{a}-\mathrm{H}, 3 \mathrm{a}-\mathrm{H}, 4 \mathrm{a}-\mathrm{H}, 5 \mathrm{a}-\mathrm{H}, 3 \mathrm{~b}-\mathrm{H}, 4 \mathrm{~b}-\mathrm{H}, 6 \mathrm{~b}-\mathrm{H}, 3 \mathrm{c}-\mathrm{H}, 5 \mathrm{c}-\mathrm{H}, 6 \mathrm{c}-$ $\mathrm{H}, 3 \mathrm{e}-\mathrm{H}, 4 \mathrm{e}-\mathrm{H}, 5 \mathrm{e}-\mathrm{H}, 6 \mathrm{e}-\mathrm{H}), 3.30(\mathrm{~m}, 1 \mathrm{H}, 5 \mathrm{~b}-\mathrm{H}), 1.60-1.40$ (3s, 9H, $3 \times$ $\left.\mathrm{CH}_{3} \mathrm{C}(\mathrm{O}) \mathrm{N}\right), 1.05\left(\mathrm{~m}, 18 \mathrm{H}, 2 \times \mathrm{C}\left(\mathrm{CH}_{3}\right)_{3}\right), 0.94(\mathrm{~d}, 3 \mathrm{H}, 6 \mathrm{a}-\mathrm{H}) .{ }^{13} \mathrm{C} \mathrm{NMR}$ $\left(150.9 \mathrm{MHz}, \mathrm{CDCl}_{3}\right) \delta 172.00-170.00(\mathrm{CO}-\mathrm{AcN}-2 \mathrm{~b}, \mathrm{CO}-\mathrm{AcN}-2 \mathrm{c}$ CO-AcN-2d), 158.00 (CO(Z)), 138.00-128.00 (C-Ph), 103.4 (C-1e), 102.1 (C-1b), 98.5 (C-1d), 94.5 (C-1c), 84.5 (C-4e), 81.9 (C-2e), 78.6-69.0 (C-1a, C-2a, C-3a, C-4a, C-3b, C-4b, C-5b, C-3c, C-4c, C-5c C-3d, C-3e, C-5e, C-6e), $66.8\left(\mathrm{CH}_{2}(\mathrm{Z})\right), 66.6(\mathrm{C}-5 \mathrm{~d}), 62.7,62.6$ (C-5a, C6b, C-6c), 55.2 (C-4d), 52.9 (C-2b), 50.1 (C-2c, C-2d), $27.9\left(\mathrm{C}^{\left.\left(\mathrm{CH}_{3}\right)_{3}\right)}\right.$ 20.3 (C-6d). MALDI-MS (positive mode, matrix DHB, THF): [M+Na] $\mathrm{m} / \mathrm{z} 2350.1$, found $2350.1 . \mathrm{C}_{138} \mathrm{H}_{158} \mathrm{~N}_{4} \mathrm{O}_{25} \mathrm{Si}_{2}$ (2328.91), calcd: $\mathrm{C} 71.17, \mathrm{H}$ $6.84, \mathrm{~N} 2.41$, found: C 71.13, H 6.93, N 2.65 .

4.1.21. 5-O-Allyl-2,3,4-tri-O-benzyl-1-O-[(2,3,4,6-tetra-O-benzyl- $\beta$-Dglucopyranosyl)-(1-3)-(2-acetylamino-4-benzyloxycarbonylamino2,4,6-trideoxy- $\alpha$-D-galactopyranosyl)-(1-4)-(2-acetylamino-3-0-ben$z y l-2$-deoxy- $\alpha$-D-galactopyranosyl)-(1-3)-(2-acetylamino-4-0-benzyl2 -deoxy- $\beta$-D-galactopyranosyl)]-D-ribitol (28). Pseudopentasacchari de 26 (177 $\mathrm{mg}, 0.75 \mathrm{mmol}$ ) was dissolved in pyridine ( $1 \mathrm{~mL}$ ) followed by addition of $\mathrm{HF}$. pyridine ( $3 \mathrm{mmol}, 100 \mu \mathrm{L}, 60 \%$ solution in pyridine). The reaction mixture was stirred overnight where TLC (petroleum ether/EtOAc $1: 1+5 \% \mathrm{MeOH}$ ) showed full conversion. The crude reaction mixture was concentrated in vacuo on silica gel and purified by flash chromatography (petroleum ether/EtOAc 1:1+MeOH gradient $0-5)$ to give diol $\mathbf{2 8}(129 \mathrm{mg}, 91 \%)$ as a colourless syrup. $[\alpha]_{\mathrm{D}}^{22}+71.1(\mathrm{c}$ 1, $\left.\mathrm{CHCl}_{3}\right) ; \nu_{\max }$ (ATR) 3275(br), $1654 \mathrm{~cm}^{-1} ;{ }^{1} \mathrm{H}$ NMR $\left(600 \mathrm{MHz}, \mathrm{CDCl}_{3}\right)$ $\delta 7.45-7.15(\mathrm{~m}, 50 \mathrm{H}, \mathrm{Ar}), 6.50-5.80(\mathrm{~m}, 1 \mathrm{H}, \mathrm{AcNH}), 5.93(\mathrm{~m}, 1 \mathrm{H}, \mathrm{All})$ $5.30(\mathrm{~d}, 1 \mathrm{H}, J=17.3 \mathrm{~Hz}, \mathrm{All}), 5.22$ (br s, $0.5 \mathrm{H}, 1 \mathrm{~d}-\mathrm{H}), 5.20$ (d, $1 \mathrm{H}$, $J=10.5 \mathrm{~Hz}$, All), 5.15 (br d, $1 \mathrm{H}, J=3.4 \mathrm{~Hz}, 1 \mathrm{c}-\mathrm{H}), 5.10-4.30(\mathrm{~m}, 25 \mathrm{H}, 1 \mathrm{~b}-$ $\mathrm{H}, 1 \mathrm{~d}-\mathrm{H}(0.5 \mathrm{H}), 2 \mathrm{c}-\mathrm{H}, 2 \mathrm{~d}-\mathrm{H}, 5 \mathrm{~d}-\mathrm{H}, 10 \mathrm{Bn}, 2 \mathrm{AcNH}), 4.60$ (m, 2c-H), 4.18 $(\mathrm{m}, 1 \mathrm{H}, 1 \mathrm{e}-\mathrm{H}), 3.55(\mathrm{~m}, 3 \mathrm{c}-\mathrm{H}), 3.45(\mathrm{~m}, 1 \mathrm{H}, 2 \mathrm{~b}-\mathrm{H}), 4.25-3.15(\mathrm{~m}, 22 \mathrm{H}$, 1-5a-H, 3-6b-H, 4-6c-H, 2-4d-H, 3-6e-H), 3.97 (m, All), 2.03, 1.84, 1.18, $1.69,1.61,1.60$ (6s, 9H, NAc), 1.10 (br d, 3H, $J=6 \mathrm{~Hz}, 6 \mathrm{~d}-\mathrm{H}) .{ }^{13} \mathrm{C}$ NMR (150.9 MHz, CDCl 3 ) $\delta 171.5$ (1C, 2NAc), 157.0 (Z), 138.7-126.8 (40C, Ar), 117.1 (All), 103.8 (C-1e), 102.5 (low intensity C-1d), 101.3 (C-1b), 96.6 (broad, C-1d), 94.3 (C-1c), 84.7, 82.2, 78.5 (2C), 77.9, 75.6, 75.1, $75.0,74.9,74.4,74.0,73.8,73.3,72.5,72.3(2 \mathrm{C}), 72.0,71.5,71.1,70.7$ $70.1,69.0,68.1,66.4(2 \mathrm{C}), 61.6,60.5,52.0,49.9,49.0,23.4,22.9,22.8$ 16.6. HRMS $\left(\mathrm{C}_{109} \mathrm{H}_{126} \mathrm{~N}_{4} \mathrm{O}_{25}\right) \quad[\mathrm{M}+2 \mathrm{Na}]^{2+} \mathrm{m} / \mathrm{z} 968.9264$, found 968.9259 .

4.1.22. 5-O-Allyl-2,3,4-tri-O-benzyl-1-O-[(2,3,4,6-tetra-O-benzyl- $\beta$-Dglucopyranosyl)-(1-3)-(2-acetylamino-4-benzyloxycarbonylamino2,4,6-trideoxy- $\alpha$-D-galactopyranosyl)-(1-4)-(2-acetylamino-3-O-ben$z y l-2$-deoxy-6-O-phosphocholine- $\alpha$-D-galactopyranosyl)-(1-3)-(2acetylamino-4-O-benzyl-2-deoxy-6-O-phosphocholine- $\beta$-D-galactopyranosyl)]-D-ribitol (30). Diol 28 (222 mg, $117 \mu \mathrm{mol}$ ) was coevaporated with toluene and dissolved in $\mathrm{MeCN}(5 \mathrm{~mL})$, containing 4 A molecular sieves (300 $\mathrm{mg}$ powder). 2-Cyanoethoxy-diisopropylamino-2trimethylammonium-ethoxy-phosphine (29, $223 \mathrm{mg}, 4$ equiv) was added together with tetrazole ( $0.45 \mathrm{M}$ in MeCN, $520 \mu \mathrm{L}, 2$ equiv) and the reaction was stirred overnight at room temperature followed by $8 \mathrm{~h}$ at $45^{\circ} \mathrm{C}$ where TLC $\left(\mathrm{CHCl}_{3} / \mathrm{MeOH} / \mathrm{H}_{2} \mathrm{O} 65: 35: 8, R_{f}=0.3\right)$ showed full conversion of starting material. The reaction mixture was cooled in an ice bath and $t-\mathrm{BuOOH}(128 \mu \mathrm{L}, 6$ equiv) was added. After $30 \mathrm{~min}$ the reaction was quenched with $\mathrm{NaHSO}_{3}(\mathrm{aq}, 1 \mathrm{M}$ ) and the reaction filtered, diluted with water and extracted with EtOAc (three times). The combined organic phases were washed with brine, dried $\left(\mathrm{MgSO}_{4}\right)$ and concentrated in vacuo followed by deprotection of the cyanoethyl group in $\mathrm{Me}_{2} \mathrm{NH}$ (33\% in EtOH). After 4 h the reaction was finished (determined from MS) and concentrated in vacuo on silica gel. Flash chromatography $\left(\mathrm{CHCl}_{3} / \mathrm{MeOH} 80: 20\right.$ to $\mathrm{CHCl}_{3} / \mathrm{MeOH} / \mathrm{H}_{2} \mathrm{O}$ 65:35:8) yielded $\mathbf{3 0}$ (186 $\mathrm{mg}, 72 \%$ ) as a colourless wax and the mono-

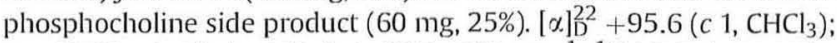
$\nu_{\max }($ ATR $) 3420(\mathrm{br}), 3273(\mathrm{br}), 1703,1659 \mathrm{~cm}^{-1} ;{ }^{1} \mathrm{H}$ NMR $(600 \mathrm{MHz}$, $\left.\mathrm{CDCl}_{3}\right) \delta 8.71($ br s, $1 \mathrm{H}, \mathrm{NH}) ; 7.73($ br s, $1 \mathrm{H}, \mathrm{NH}), 7.51-7.11(\mathrm{~m}, 51 \mathrm{H}, \mathrm{Ar}$, $\mathrm{NH}), 5.89(\mathrm{~m}, 1 \mathrm{H}$, All $), 5.29$ (br s, $1 \mathrm{H}, 1 \mathrm{c}-\mathrm{H}), 5.25$ (dd, $1 \mathrm{H}, J=1.5$, $17.2 \mathrm{~Hz}, \mathrm{All}$ ), 5.22 (br s, 1H, NH), $5.17(\mathrm{~d}, 1 \mathrm{H}, J=10.5 \mathrm{~Hz}, \mathrm{All}), 5.11$ (d, $1 \mathrm{H}$, $\left.J=12.3 \mathrm{~Hz}, \mathrm{CH}_{2}(\mathrm{Z})\right), 5.02\left(\mathrm{~d}, 1 \mathrm{H}, J=12.3 \mathrm{~Hz}, \mathrm{CH}_{2}(\mathrm{Z})\right), 4.92-4.40(\mathrm{~m}, 4 \mathrm{H}$, 1b-H, 1d-H), 4.81-4.44 (m, 24H, 1e-H, 2c-H, 2d-H, 5d-H, 10Bn), 4.34 (m, 1H, 2b-H), 4.30-3.38 (m, 35H, 2e-H, 3d-H, 4d-H, 3-6c-H, 1-5a-H, $\left.\mathrm{CH}_{2}-\mathrm{All}, 2 \times \mathrm{OCH}_{2} \mathrm{CH}_{2} \mathrm{~N}\left(\mathrm{CH}_{3}\right)_{3}\right), 2.98\left(\mathrm{~s}, 9 \mathrm{H}, \mathrm{OCH}_{2} \mathrm{CH}_{2} \mathrm{~N}\left(\mathrm{CH}_{3}\right)_{3}\right), 2.91$ (s, $\left.9 \mathrm{H}, \mathrm{OCH}_{2} \mathrm{CH}_{2} \mathrm{~N}\left(\mathrm{CH}_{3}\right)_{3}\right), 1.90,1.83,1.61(3 \times \mathrm{s}, 9 \mathrm{H}, 3 \times \mathrm{NAc}$ ), 0.96 (br d, $3 \mathrm{H}, J \approx 6 \mathrm{~Hz}, 6 \mathrm{~d}-\mathrm{H}) .{ }^{13} \mathrm{C}$ NMR $\left(150.9 \mathrm{MHz}, \mathrm{CDCl}_{3}\right.$ ) (from HSQC) $\delta 134.5$ (CH-All), 138-128 (Ar), $116.8\left(\mathrm{CH}_{2}-\mathrm{All}\right), 103.6(\mathrm{C}-1 \mathrm{e}), 100.6$ (C-1b), 97.4 (C-1d), 92.1 (C-1C), 84.3 (C-3e), 81.9 (C-2e), 78.3, 78.1, 77.9, 75.8, 75.1-71.9 (Bn), 74.5, 73.4, 73.1, 72.1, 72.9, 72.0, 70.1, 70.1, $69.8,69.0,66.4\left(\mathrm{CH}_{2}(\mathrm{Z})\right), 65.9,65.8,65.2,64.7,59.3,54.1$ (3C, $\left.\mathrm{OCH}_{2} \mathrm{CH}_{2} \mathrm{~N}\left(\mathrm{CH}_{3}\right)_{3}\right), 53.9\left(3 \mathrm{C}, \quad \mathrm{OCH}_{2} \mathrm{CH}_{2} \mathrm{~N}\left(\mathrm{CH}_{3}\right)_{3}\right), 49.9,48.8,22.9$ (NAc), 22.9 (NAc), 22.5 (NAc), 16.5 (C-6g). ${ }^{31} \mathrm{P} \mathrm{NMR} \mathrm{(242} \mathrm{MHz,} \mathrm{CDCl}_{3}$ ) $\delta-1.53,-1.72$. HRMS $\left(\mathrm{C}_{119} \mathrm{H}_{150} \mathrm{~N}_{6} \mathrm{O}_{31} \mathrm{P}_{2}\right)[\mathrm{M}+2 \mathrm{H}]^{2+} \mathrm{m} / \mathrm{z} 1112.0000$, found 1111.9996 .

4.1.23. 2,3,4-Tri-O-Benzyl-1-O-I(2,3,4,6-tetra-O-benzyl- $\beta$-D-glucopyranosyl)-(1-3)-(2-acetylamino-4-benzyloxycarbonylamino-2,4,6trideoxy-c $(x-D$-galactopyranosyl)-(1-4)-(2-acetylamino-3-0-benzyl-2deoxy-6-0-phosphocholine- $\alpha-1-$-galactopyranosyl)-(1-3)-(2acetylamino-4-O-benzyl-2-deoxy-6-O-phosphocholine- $\beta$-D-galactopyranosyl)]-D-ribitol (31). Fully protected pseudopentasaccharide 30 (100 mg, $45 \mu \mathrm{mol}$ ) was dissolved in $\mathrm{EtOH}(5 \mathrm{~mL})$ and $\left(\mathrm{Ph}_{3} \mathrm{P}\right)_{3} \mathrm{RuCl}_{2}$ (22 mg, $2.25 \mu \mathrm{mol}, 0.5$ equiv) was added together with DBU (1 drop) followed by heating to reflux for $30 \mathrm{~min}$. The reaction mixture was diluted with $\mathrm{MeOH}$, cooled on ice bath and $\mathrm{TsOH} \cdot \mathrm{H}_{2} \mathrm{O}$ $(10 \mathrm{mg}$ ) added. After $3.5 \mathrm{~h}$ at room temperature no further reaction took place and the reaction was quenched with $\mathrm{Et}_{3} \mathrm{~N}$, concentrated on silica gel and purified by flash chromatography $\left(\mathrm{CHCl}_{3} / \mathrm{MeOH}\right.$ $80: 20$ to $\mathrm{CHCl}_{3} / \mathrm{MeOH} / \mathrm{H}_{2} \mathrm{O} 65: 35: 8$ ) to yield 31 (58 $\mathrm{mg}, 68 \%$ ) as a colourless wax and unreacted starting material $(22 \mathrm{mg})$. Yield based on recovered starting material $87 \%$. $[\alpha]_{\mathrm{D}}^{22}+95.3\left(c 1, \mathrm{CHCl}_{3}\right)$; $\nu_{\max }(\mathrm{ATR}) 3450(\mathrm{br}), 3275(\mathrm{br}), 1658 \mathrm{~cm}^{-1} ;{ }^{1} \mathrm{H} \mathrm{NMR}\left(600 \mathrm{MHz}, \mathrm{CDCl}_{3}\right)$ $\delta 8.86$ (br s, 0.6H, NH), 7.77 (br s, 0.55H, NH), 7.42-7.02 ( $\mathrm{m}, 51 \mathrm{H}, \mathrm{Ph}$, $\mathrm{NH}), 5.21$ (br s, $1.5 \mathrm{H}, 1 \mathrm{c}-\mathrm{H}, \mathrm{NH}(\mathrm{Z})), 5.06\left(\mathrm{~d}, 1 \mathrm{H}, \mathrm{J}=12.4 \mathrm{~Hz}, \mathrm{CH}_{2}(\mathrm{Z})\right.$ ), $4.95\left(\mathrm{~d}, 1 \mathrm{H}, J=12.4 \mathrm{~Hz}, \mathrm{CH}_{2}(\mathrm{Z})\right), 4.80(\mathrm{~m}, 1 \mathrm{H}, 1 \mathrm{~b}-\mathrm{H}), 4.76(\mathrm{~m}, 1 \mathrm{H}, 1 \mathrm{~d}-\mathrm{H})$ $4.66(\mathrm{~m}, 1 \mathrm{H}, 1 \mathrm{e}-\mathrm{H}), 4.60(\mathrm{~m}, 1 \mathrm{H}, 2 \mathrm{c}-\mathrm{H}) ; 4.52(2 \mathrm{~b}-\mathrm{H}), 4.41(5 \mathrm{~d}-\mathrm{H})$, $4.85-4.40(\mathrm{~m}, 18 \mathrm{H}, \mathrm{Bn}), 4.15(2 \mathrm{~d}-\mathrm{H}), 4.35-3.20(\mathrm{~m}, 32 \mathrm{H}, 3-6 \mathrm{e}-\mathrm{H}, 3-$ 4d-H, 3-6c-H, 3-6e H, 1-5a-H, $\left.2 \times \mathrm{OCH}_{2} \mathrm{CH}_{2} \mathrm{~N}\left(\mathrm{CH}_{3}\right)_{3}\right), 3.35(\mathrm{~m}, 1 \mathrm{H}, 2 \mathrm{e}-$ H), 2.89 (br s 9H, $\left.\quad \mathrm{OCH}_{2} \mathrm{CH}_{2} \mathrm{~N}\left(\mathrm{CH}_{3}\right)_{3}\right), 2.86$ (br s, $9 \mathrm{H}$, $\left.\mathrm{OCH}_{2} \mathrm{CH}_{2} \mathrm{~N}\left(\mathrm{CH}_{3}\right)_{3}\right), 1.81$ (s, 3H, NAc), 176 (s, 3H, NAc), 1.52 (s, 3H, NAc), $0.88(\mathrm{~m}, 3 \mathrm{H}, 6 \mathrm{~d}-\mathrm{H}) .{ }^{13} \mathrm{C}$ NMR $\left(150.9 \mathrm{MHz}, \mathrm{CDCl}_{3}\right) \delta 171.6(\mathrm{C}=0$ $\mathrm{NAc}), 171.5(\mathrm{C}=\mathrm{ONAc}), 171.3(\mathrm{C}=\mathrm{ONAc}), 156.8(\mathrm{C}=\mathrm{OZ}), 138.9,138.8$ (3C), 138.7, 138.5, 138.3, 138.0, 136.9, 128.7-127.6 (Ar), 104.0 (C-1e), 101.0 (C-1b), 97.3 (C-1d), 92.3 (C-1c), 84.6 (C-3e), 82.1 (C-2e), 79.9, 79.2, 78.7, 78.1, 77.9, 75.9, 75.4, 75.1, 74.9, 74.4, 74.0, 73.7 (2C), 73.6, 73.4, 73.1, 72.6, 72.4, 72.1, 71.4, 71.0, 70.5, 69.2, 67.8, 66.6, 66.2, 66.2. $66.1,64.9,61.5,59.4,59.3,55.4$ (C-3-6e, C-3-5d, C-3-6c, C-3-6b, C-15 a, $\left.2 \times \mathrm{CH}_{2} \mathrm{CH}_{2} \mathrm{~N}\left(\mathrm{CH}_{3}\right)_{3}, \mathrm{CH}_{2} \mathrm{Z}, 9 \times \mathrm{Bn}\right), 54.2\left(\mathrm{CH}_{2} \mathrm{CH}_{2} \mathrm{~N}\left(\mathrm{CH}_{3}\right)_{3}\right), 53.6$ $\left(\mathrm{CH}_{2} \mathrm{CH}_{2} \mathrm{~N}\left(\mathrm{CH}_{3}\right)_{3}\right), 50.0(\mathrm{C}-2 \mathrm{~d}), 49.6$ (C-2c), 49.1 (C-2b), 29.8 (NAc), 
23.2 (NAc), 22.8 (NAc), 16.8 (C-6d). HRMS $\left(\mathrm{C}_{116} \mathrm{H}_{146} \mathrm{~N}_{6} \mathrm{O}_{31} \mathrm{P}_{2}\right)$ $[\mathrm{M}+2 \mathrm{Na}]^{2+} \mathrm{m} / \mathrm{z} 1113.9663$, found 1113.9647 .

4.1.24. 1-O-I( $\beta$-D-Glucopyranosyl)-(1-3)-(2-acetylamino-4-amino2,4,6-trideoxy- $\alpha$-D-galactopyranosyl)-(1-4)-(2-acetylamino-2deoxy-6-O-phosphocholine- $\alpha$-D-galactopyranosyl)-(1-3)-(2acetylamino-2-deoxy-6-O-phosphocholine- $\beta$-D-galactopyranosyl)]-Dribitol (3). Pseudopentasaccharide 31 (55 mg, $28 \mu \mathrm{mol}$ ) was dissolved in MeOH/EtOAc $(1: 1,3 \mathrm{~mL})$ and Pearlman's catalyst was added. The mixture was stirred overnight under a hydrogen atmosphere. The reaction mixture was filtered and concentrated in vacuo. The crude product was not fully debenzylated, therefore it was dissolved in $\mathrm{MeOH}(4 \mathrm{~mL})$ and hydrogenated with $\mathrm{Pd} / \mathrm{C}(10 \%)$ under a hydrogen atmosphere overnight. The concentrated product was purified by SEP-Pak $C_{18}$ with water as solvent to give $\mathbf{3}$ (24 mg) containing some salt impurities; they were removed by GPC on Sephadex G10 $(2.5 \times 120 \mathrm{~cm}$, GE Healthcare $)$ in pyridine/acetic acid/ water $(4 / 10 / 1000, v / v / v, p H 4.7)$. The eluate $(0.3 \mathrm{~mL} / \mathrm{min})$ was monitored with a refractometer. The eluent was lyophilized to give $3(15 \mathrm{mg}, 44 \%)$ as a white powder. For NMR data see Table 1. HRMS $\left(\mathrm{C}_{45} \mathrm{H}_{86} \mathrm{~N}_{6} \mathrm{O}_{29} \mathrm{P}_{2}\right)[\mathrm{M}+\mathrm{H}], \mathrm{m} / z$ 1237.499, $[\mathrm{M}+\mathrm{Na}]^{+} 1259.482$, found: $m / z 1237.503,1259.489$.

\section{Acknowledgements}

This work was supported by the University of Konstanz, the Deutsche Forschungsgemeinschaft and the Fonds der Chemischen Industrie.-C.M.P. is particularly greatful for a fellowship form the Danish Agency for Science, Technology and Innovation.

\section{References and notes}

1. Westphal, O.; Lüderitz, O.; Keiderling, W. Zentralbl. Bakteriol. Parasitenkd. Infektionskrankr. Hyg. 1952, 158, 152-160.

2. Zähringer, U.; Lindner, B.; Inamura, S.; Heine, H.; Alexander, C. Immunobiology 2008, 213, 205-224.

3. Greenberg. J. W.; Fischer, W.; Joiner, K. A. Infect. Immun. 1996, 64, 3318-3325: Fischer, W. Microb. Drug Resist. 1997, 3, 309-325.

4. Seo, H. S.; Cartee, R. T.; Pritchard, D. G.; Nahm, M. H. J. Bacteriol. 2008, 190 2379-2387; Bergström, N.; Jansson, P.-E.; Kilian, M.; Sorensen, U. B. S. Eur: J. Biochem. 2003, 270, 2157-2162.

5. Zangwill, K. M.; Vadheim, C. M.; Vannier, A. M.; Hemenway, L. S.; Greenberg, D. P. Ward, J. I. J. Infect. Dis. 1996, 174, 752-759.

6. Jedrzejas, M. J. Microbiol. Mol. Biol. Rev, 2001, 65, 187-207.

7. Lowy, F. D. N. Engl. J. Med. 1998, 339, 520-532.

8. Fischer, W.; Behr, T.; Hartmann, R.; Peter-Katalinic, J.; Egge, H. Eur. J. Biochem. 1993, 215, 851-857; Behr, T.; Fischer, W.; Peter-Katalinic, J.; Egge, H. Eur. J. Biochem. 1992, 207, 1063-1075.

9. Draing, C.; Pfitzenmaier, M.; Zummo, S.; Mancuso, G.; Geyer, A.; Hartung, T.; von Aulock, S. J. Biol. Chem. 2006, 281, 33849-33859.

10. This division into lipid anchor and repeating unit was introduced by Fischer et al., Ref 3. Recently, a different division between lipid anchor and repeating unit was proposed: see Ref. 4.

11. Pedersen, C. M.; Figueroa-Perez, I.; Lindner, B.; Ulmer, A. J.; Zährringer, U.; Schmidt, R. R. Angew. Chem. 2010, 122, 2639-2644; Angew. Chem., Int. Ed. 2010, $49,2585-2590$

12. Pedersen, C. M.; Figueroa-Perez, I.; Boruwa, J.; Lindner, B.; Ulmer, A. J.; Zähringer, U.; Schmidt, R. R. Chem.-Eur. J. 2010, 16, 12627-12641.

13. Qui, H.; Grindley, T. B. Can. J. Chem. 1999, 77, 481-494.

14. Schmidt, R. R. Angew. Chem. 1986, 98, 213-236; Angew. Chem., Int. Ed. Engt. 1986, 25, 212-235: Schmidt, R. R. Kinzy, W. Adv, Carbohydr Chem. Biochem. 1994, 50, 21-123: Zhu, X. Schmidt, R. R. Angew. Chem, 2009, 121, 1932-1967; Angew. Chem., Int. Ed. 2009, 48, 1900-1934.

15. Alper, P. B.; Hung, S.-C.; Wong, C.-H. Tetrahedron Lett. 1996, 37, 6029-6032; Yan, R.; Wang, F; Wu, Y.; Zhang, L.-H.; Ye, X. S. Tetrahedron Lett. 2005, 46, $8993-8995$

16. Andreotti, A. H.; Kahne, D. J. Am. Chem. Soc. 1993, 115, 3352-3353.

17. Liang, L.; Chan, T.-H. Tetrahedron Lett. 1998, 39, 355-358.

18. Kanie, O.; Crawley, S. C.; Palcic, M. M.; Hindsgaul, O. Carbohydr: Res. 1993, 243, 139-164.

19. Schmidt, R. R.; Rücker; E. Tetrahedron Lett. 1980, 21, 1421-1424; Schmidt, R. R.; Behrendt, M.; Toepfer; A. Synlett 1990, 694-697.

20. Figueroa-Perez I. Dissertation, Universität Konstanz, 2007.

21. Hada, N.; Shida, Y.; Shimamura, H.; Sonoda, Y.; Kasahara, T.; Sugita, M.; Takeda, T. Carbohydr: Res. 2008, 343, 2221-2228.

22. Corey, E. J.; Suggs, J. W. J. Org. Chem. 1973, 38, 3224.

23. Cheshev, P. E.; Kononov, L. O.; Tsvetkov, Y. E.; Shashkov, A. S.; Nifanticv, N. E. Russ. J. Bioorg. Chem. 2002, 28, 419-429; Bioorg. Khim. 2002, 28, 462-473. 